\title{
Discordant vs. Harmonious Selves: The Effects of Identity Conflict and Enhancement on Sales Performance in Employee-Customer Interactions
}

\section{Citation}

Ramarajan, Lakshmi, Nancy Rothbard, and Steffanie Wilk. "Discordant vs. Harmonious Selves: The Effects of Identity Conflict and Enhancement on Sales Performance in Employee-Customer Interactions." Academy of Management Journal 60, no. 6 (December 2017): 2208-2238.

\section{Published Version}

https://doi.org/10.5465/amj.2014.1142

\section{Permanent link}

http://nrs.harvard.edu/urn-3:HUL.InstRepos:41845088

\section{Terms of Use}

This article was downloaded from Harvard University's DASH repository, and is made available under the terms and conditions applicable to Other Posted Material, as set forth at http:// nrs.harvard.edu/urn-3:HUL.InstRepos:dash.current.terms-of-use\#LAA

\section{Share Your Story}

The Harvard community has made this article openly available.

Please share how this access benefits you. Submit a story.

\section{Accessibility}




\title{
DISCORDANT VS. HARMONIOUS SELVES: THE EFFECTS OF IDENTITY CONFLICT AND ENHANCEMENT ON SALES PERFORMANCE IN EMPLOYEE-CUSTOMER INTERACTIONS
}

\author{
LAKSHMI RAMARAJAN \\ Harvard University \\ NANCY P. ROTHBARD \\ University of Pennsylvania \\ STEFFANIE L. WILK \\ The Ohio State University
}

\begin{abstract}
Across multiple studies, we examine how identity conflict and enhancement within people affect performance in tasks that involve interactions between people. We also examine two mechanisms: role-immersion, operationalized as intrinsic motivation, and role-taking, operationalized as perspective-taking. In Study 1, a longitudinal field study of customer service representatives $(n=763)$ who simultaneously identify with multiple brands they represent to customers, we examine the relationships between identity conflict and enhancement, on the one hand, and objective sales performance, on the other. We find independent effects for identity conflict and enhancement on intrinsic motivation, perspective-taking and performance, such that identity conflict negatively and enhancement positively affects all three variables above and beyond average identification. Intrinsic motivation further mediates the relationships between identity conflict and enhancement on sales in a direction consistent with our theorizing. However, while significant, perspective-taking does not mediate these relationships in the expected direction, because it has a negative effect on sales. In Studies $2 a$ and $2 b$, we strengthen causal inference using an experimental moderation-of-process approach to constructively replicate and extend our findings. The paper demonstrates how multiple identities within people can have consequences for performance in tasks that involve interactions between people.
\end{abstract}

Employees can simultaneously have multiple work identities. For example, an employee may define him or herself as a technical expert and boss on a team as well as a provider of different services and products to customers. Yet, beyond the importance of each identity, how employees experience the

We would like to thank our colleagues for their conversations and feedback on earlier versions of this paper: Michel Anteby, Sigal Barsade, Julie Battilana, Francesca Gino, Leslie John, Spencer Harrison, Celia Moore, Otilia Obodaru, Jennifer Petriglieri, Mike Pratt, Erin Reid, and Michele Williams. We thank Chris Foster for assistance with data analysis. We are also grateful to Christy Ley, Jean Sohn, Serenity Lee, and Emily LeRoux-Rutledge for research assistance. We thank our editor, Aparna Joshi, and three anonymous reviewers for their constructive feedback throughout the review process. This research was supported by funding from Harvard Business School, the Wharton School, and Ohio State University. relationship between their multiple work identities can be conflicting or enhancing. These identity relationships may influence how we interact with others and perform in organizations. We examine how an employee's experience of his or her multiple work identities, as conflicting or enhancing, can affect how he or she may perform in tasks that require interpersonal interaction such as those between employees and customers.

Identity is a subjective claim about oneself that acts as a deeply held guide for one's thoughts, motivations, and behaviors (Ashmore, Deaux, \& McLaughlinVolpe, 2004; Burke \& Stets, 2009). Because individuals inhabit multiple roles and groups simultaneously, scholars have long discussed the principle that people have multiple identities (James, 1983; Markus \& Nurius, 1986; Rosenberg, 1997; Thoits, 1983); however, multiple identities have not traditionally been the focus of organizational research (Ashforth \& 
Johnson, 2001; Pratt \& Foreman, 2000; Ramarajan, 2014). Following the literature, we define multiple identities as "two or more meanings that individuals attach to themselves as a function of their multiple social group memberships ... and roles" (Creary, Caza, \& Roberts, 2015: 5). Identities have been conceptualized at various levels of self, including personal, i.e., identities that distinguish oneself from others (e.g., kind); relational, i.e., identities that derive from role relationships (e.g., employee vis-à-vis customer); and group, i.e., those that derive from collectives (e.g., organization) (Brewer \& Gardner, 1996; Brickson, 2013; Kreiner, Hollensbe, \& Sheep, 2006; Sluss \& Ashforth, 2007). We focus on multiple work-role identities, or "the goals, values, beliefs, norms" associated with multiple work roles (Ashforth, 2001: 6), and the relationships among these identities.

Existing research has examined some aspects of multiple identities, in particular the number and the strength of people's identification with multiple targets (e.g., my role, my organization) (Ashforth \& Johnson, 2001; George \& Chattopadhyay, 2005; Johnson, Morgeson, Ilgen, Meyer, \& Lloyd, 2006; Lipponen, Helkama, Olkkonen, \& Juslin, 2005; Pratt \& Foreman, 2000; Thoits, 1983). However, recent conceptual work has highlighted the importance of examining how identities are intrapsychically related to one another (Ramarajan, 2014). While some research has highlighted the importance of identity conflict, defined as the degree of tension, or opposition, among a person's identities (Benet-Martinez \& Haritatos, 2005; Greenhaus \& Beutell, 1985; Horton, Bayerl, \& Jacobs, 2014), less research has examined identity enhancement, defined as the degree of complementarity and synergy among a person's identities (Dutton, Roberts, \& Bednar, 2010; Greenhaus \& Powell, 2006; Pratt \& Foreman, 2000; Rothbard \& Ramarajan, 2009). Here we examine both identity conflict and enhancement simultaneously, as the absence of identity conflict may not be the same as the presence of identity enhancement (and vice versa).

Identity conflict and enhancement not only reflect our subjective experiences of who we are, but also have important consequences for individuals and organizations. Current research has provided insight into how multiple identities affect people's wellbeing (Brook, Garcia, \& Fleming, 2008; Marcussen, 2006; Shih \& Sanchez, 2005; Thoits, 1983) and performance in individually focused tasks (Cheng, Sanchez-Burks, \& Lee, 2008; Tadmor, Tetlock, \& Peng, 2009). We extend this work by investigating how identity conflict and enhancement affect performance in tasks that involve interpersonal interactions such as employee-customer interactions. Work involving employee-customer interactions is a type of "people work" (Brotheridge \& Grandey, 2002; Hochschild, 1983; Wilk \& Moynihan, 2005; Rafaeli, 1989) and forms a large and growing part of the economy (Batt, Hunter, \& Wilk, 2003; Henderson, 2013).

While much past research on employee-customer interactions has focused on emotional labor (Brotheridge \& Grandey, 2002; Hochschild, 1983; Wharton, 2009), some scholars argue that the identity of the focal employee plays an important role in people work (Ashforth \& Humphrey, 1993). Recent scholarship demonstrates that customer service employees' identification with the task allows them to authentically represent the product to the customer (Yagil \& Medler-Liraz, 2013) and that identification with the organization, customer, or brand affect customer service behaviors and sales (Hughes \& Ahearne, 2010; Johnson \& Ashforth, 2008). Consistent with this identity-based perspective, we examine employees' identification with the different brands they represent. These are work-role identities because the employees' work role is to represent the brand to customers. Identity conflict and enhancement are particularly important to examine in the context of customer-facing jobs where employees frequently have to represent brands which stand for values that might, or might not, be compatible with one another. Consider an employee who strongly identifies with two salient work roles that involve representing two distinct brands each of which stands for an important value that she holds-one a socially conscious brand, standing for her value of helping others, and the other a luxury brand, standing for her value of enjoying life. The employee may experience identity conflict if she thinks that representing the luxury brand interferes with representing the socially conscious brand because the two values are opposed: for instance, if she thinks focusing on enjoying life detracts from helping others. Conversely, she may experience identity enhancement if she thinks that representing the luxury brand facilitates representing the socially conscious brand because the two values are complementary: for instance, if she thinks one can enjoy life more if one helps others. We investigate how the experiences of identity conflict and enhancement among brand identities of a focal customer service employee may ultimately affect their sales performance.

To understand how identity conflict and enhancement affect performance in tasks that involve 
interpersonal interaction, we build on identity theory (Burke \& Stets, 2009; Stryker, 2008; Stryker \& Burke, 2000) and early work from the symbolic interactionist tradition (Goffman, 1961; Mead, 1934; Turner, 1956). Our theoretical framework proposes that identity conflict and enhancement affect performance in interaction-based tasks via role-immersion and role-taking: two core elements of identity enactment. Role-immersion refers to focusing on and completely engaging in one's role and is related to flow and intrinsic motivation (Kahn, 1990; Scott, 2015). Role-taking refers to focusing on the other party's role and taking their point of view (Turner, 1956) and is related to perspective-taking (Grant \& Berry, 2011). Both intrinsic motivation and perspective-taking affect performance in tasks, such as sales, that involve interpersonal interactions (Parker \& Axtell, 2001; Spiro \& Weitz, 1990).

By linking conflict and enhancement among multiple identities within individuals to performance deriving from interactions between individuals (in this case, employees and customers), we contribute to research on multiple identities in several ways. First, we respond to the need for more research into the psychological experience of multiple identities (Ashforth, Harrison, \& Corley, 2008; Burke \& Stets, 2009). Prior research has largely sidestepped the complexity of multiple identities by relying on notions of identity salience, in which situational triggers make a single identity salient (Stryker \& Serpe, 1994; Tajfel \& Turner, 1987). Yet the single identity approach does not reflect the reality of today's organizations. We build on and extend newer approaches that suggest multiple identities should be examined simultaneously and in relationship to one another (Brook et al., 2008; Cheng et al., 2008; Ramarajan, 2014).

Second, existing research on relationships among multiple identities has largely focused on identity conflict (Ashforth et al., 2008; Hirsh \& Kang, 2016; Horton et al., 2014). Identity enhancement has been less explored theoretically and empirically (Ashforth et al., 2008; Dutton et al., 2010) in part because it has been conceptualized as the opposite of conflict (Brook et al., 2008; Pratt \& Foreman, 2000). However, recent research on multiple roles and identities has argued that scholars should view identity enhancement and conflict as distinct constructs (Dutton et al., 2010; Ramarajan, 2014; Rothbard, 2001; Rothbard \& Ramarajan, 2009). Our paper advances this research by examining both identity conflict and identity enhancement (Dutton et al., 2010; Rothbard \& Ramarajan, 2009) because the absence of identity conflict may not be equivalent to the presence of identity enhancement (and vice-versa). Last, we contribute by focusing on the mechanisms that link identities to performance in tasks that involve interpersonal interaction. Specifically, we examine how identity conflict and enhancement relate to psychological processes that are critical for interdependent work, such as perspective-taking and intrinsic motivation, and link those to performance in a "people work" context.

\section{THEORETICAL FRAMEWORK AND HYPOTHESES}

\section{Multiple Identities}

Scholars have suggested numerous ways of conceptualizing and operationalizing multiple identities. One common approach is to examine the number of identities (Pratt \& Foreman, 2000; Thoits, 1983). A second approach is to investigate the level of identification, whether in absolute or relative terms. For instance, Ashforth and Johnson (2001) suggest we examine relative salience, while Brook et al. (2008) examine the average level of identification across identities. A third approach is to examine how individuals psychologically experience the relationships among their multiple identities, specifically whether they experience their identities as conflicting or enhancing (Brook et al., 2008; Burke \& Stets, 2009; Pratt \& Foreman, 2000; Ramarajan, 2014). This approach builds on the idea that identities can be co-activated or simultaneously salient (Blader, 2007; Rothbard \& Ramarajan, 2009) rather than adopting the view that identities are arranged in a salience hierarchy (Stryker \& Serpe, 1982). Therefore, the baseline is not the absence of multiple identities but the lack of a relationship between salient identities. This approach also challenges the assumption that having multiple identities means they are automatically conflicting with one another. Instead, we examine both conflicting and enhancing relationships between simultaneously salient identities, controlling for or holding constant the number or salience of the identities to understand how the experience of multiple identities affects performance in interpersonal interactions. ${ }^{1}$

\footnotetext{
${ }^{1}$ Our examination of multiple work-role identities is distinct from relational identification (Sluss \& Ashforth, 2007). Relational identification is the degree to which a role relationship (e.g., a subordinate's identification with a manager), either generalized or particularized, is part of the focal employee's self-concept (Sluss, Ployhart, Cobb, \& Ashforth, 2012; Sluss et al., 2010). In contrast, we examine an individual's own identification with work roles and the conflict and enhancement between these identities.
} 


\section{Identity Conflict and Enhancement}

Identity conflict has sometimes been conceptualized as the opposite of identity enhancement, such that greater identity conflict by definition means lower identity enhancement (Brook et al., 2008; Pratt $\&$ Foreman, 2000). However, research from a number of related areas has suggested that they may be orthogonal to one another. ${ }^{2}$ Following this research, we do not assume that the absence of identity conflict is the equivalent of identity enhancement and viceversa. Rather, we investigate identity conflict and enhancement as independent of one another, meaning that the effects we propose below should not negate one another, but rather the effect of identity conflict should exist when accounting for the presence of identity enhancement and vice versa.

Identity conflict is the experience where one is torn between, or must give up, the meanings, values, and behaviors associated with one identity in order to maintain or preserve another (Ashforth et al., 2008; Burke \& Stets, 2009; Horton et al., 2014). James (1983: 282) called this psychological experience of identity conflict a "discordant splitting." Research suggests that identity conflict is a common experience across a wide variety of identities, from conflict between the ethnic and national identities of immigrants (Benet-Martinez \& Haritatos, 2005) to tension between the work and nonwork identities of professionals (Kreiner et al., 2006). This experience creates dissonance and insecurity regarding one's

\footnotetext{
${ }^{2}$ Evidence from the work-family domain supports the view that identity conflict and enhancement need not be opposite ends of a single continuum (Greenhaus \& Powell, 2006; Rothbard, 2001). Rather, they can be independent, such that one can experience both enhancement and conflict between the same identities, alternately over time, or across situations. Greenhaus and Powell (2006) reviewed 15 studies that examined conflict and enrichment between work and family roles and concluded that the two constructs are independent. Furthermore, theory and research suggests that there are a number of positive and negative psychological processes that are not opposites of one another, but rather orthogonal (Carver \& White, 1994; Taylor, 1991; Watson, Clark, \& Tellegen, 1988). For example, research on Behavior Activation and Inhibition Systems suggests that two key independent dimensions underlie motivation and behavior, approach, and avoidance (Carver \& White, 1994). Moreover, this framework suggests that these systems activate different neural processes such that more avoidance of a stimulus is not equivalent to less approach (Gray, Burgess, Schaefer, Yarkoni Larsen, \& Braver, 2005; Hirsh \& Kang, 2016). They are simply separate systems.
}

sense of self (Marcussen, 2006; Thoits, 1991). Because a core function of identities is to guide our thoughts and behaviors (Burke \& Stets, 2009; Stryker \& Serpe, 1982), identity conflict also depletes one's motivational and cognitive resources. Engaging in a struggle to define oneself exhausts motivational resources by draining one of energy (Marks, 1977; Rothbard, 2001; Thoits, 1991) and creating stress (Hirsh \& Kang, 2016). When multiple identities are salient and at odds, people are likely to respond by disregarding conflicting identities (Hugenberg \& Bodenhausen, 2004; Petriglieri, 2011) and by allocating cognitive resources toward making choices about and regulating their behavior (Baumeister, 2002; Lyubomirsky \& Nolen-Hoeksema, 1993; Rothbard, 2001). Thus:

Hypothesis 1. Identity conflict is negatively related to performance in tasks that involve interpersonal interactions.

Identity enhancement is the experience of a sense of complementarity and wholeness in who one is (Brook et al., 2008; Cast \& Burke, 2002). When experiencing identity enhancement, more than one set of meanings, values, and behaviors of the self are verified (Dutton et al., 2010; Greenhaus \& Powell, 2006; Rothbard \& Ramarajan, 2009). James (1983: 282) called this psychological experience of enhancement a "harmonious division." Less empirical research exists on identity enhancement; however, we draw on related research to understand how identity enhancement may affect performance. Work-family research suggests that people can experience synergy between their work and nonwork identities (Greenhaus \& Powell, 2006; Ruderman, Ohlott, Panzer, \& King, 2002; Tiedje, Wortman, Downey, Emmons, Biernat, \& Lang, 1990). In particular, identity enhancement can create motivational resources because people gain energy from their identification with various roles, groups, and relationships (Creary et al., 2015; Marks, 1977; Rothbard, 2001; Thoits, 1983). Moreover, the experience of identity enhancement may also improve task performance because cognitive resources are not being allocated toward identity concerns, and so are likely more available for work demands (Baumeister, Bratslavsky, Muraven, \& Tice, 1998; Hirsh \& Kang, 2016). Thus:

Hypothesis 2. Identity enhancement is positively related to performance in tasks that involve interpersonal interactions. 


\section{Mechanisms Linking Work-Role Identities to Interpersonal Interaction}

What explains the direct effects of identity conflict and enhancement on performance in tasks that involve interpersonal interactions? The above research points to two important types of mechanisms: motivational and cognitive resources, which are drained or amplified by identity conflict and enhancement, respectively. To build a theoretical framework to guide our choice of mechanisms in tasks that involve interpersonal interactions, we draw on identity theory (Burke \& Stets, 2009; Stryker, 2008; Stryker \& Burke, 2000). Classic approaches to identity theory have both an internal self-definition component and an interaction component (Burke \& Stets, 2009; Sluss, van Dick, \& Thompson, 2010; Stryker \& Statham, 1985).

Drawing on identity theory and symbolic interactionism (Burke \& Stets, 2009; Mead, 1934; Stryker, 2008; Stryker \& Burke, 2000; Turner, 1956), we suggest that role-immersion, operationalized as intrinsic motivation, and role-taking, operationalized as perspective-taking, are key motivational and cognitive mechanisms through which identities drive behaviors in interpersonal interaction (see Figure 1). In the context of multiple identities, we argue that intrinsic motivation and perspectivetaking explain the relationship between identity conflict and enhancement, on the one hand, and performance in tasks that involve interpersonal interaction, on the other (see Figure 2).

\section{Role-Immersion: Multiple Identities, Intrinsic Motivation, and Performance}

Role identities drive behavior in an interaction by focusing us on our own experience of our role (Callero, 1985; Reitzes \& Burke, 1980). A key distinction between a role and a role identity is that a role can be enacted strictly through meeting external expectations or obligations, while identity involves internalized meanings and expectations (Sluss et al., 2010; Stryker \& Burke, 2000) and is enacted as a form of self-expression (Ashforth \& Humphrey, 1993; Katz \& Kahn, 1978; Waterman, 1990). Identifying with a role leads to more roleimmersion, which is related to the psychological engagement in the role because it is inherently fulfilling (Kahn, 1990; Rothbard \& Edwards, 2003). Kahn (1990) argued that "people have dimensions of themselves ... they prefer to use and express in the course of role performances" (p. 700). The experience of immersion in the work role is consistent with the literature on flow (Czikszentmihalyi, 1982) and intrinsic motivation, which defines intrinsic motivation as a self-determined sense of being inherently interested in and enjoying the work itself (Deci \& Ryan, 2000; Gagné \& Deci, 2005; Leonard, Beauvais, \& Scholl, 1999).

Identity conflict. Identity conflict is likely to drain intrinsic motivation, decreasing performance. Identity conflict reduces our intrinsic motivation toward our work because people who experience identity conflict feel stuck, paralyzed, or caught between

FIGURE 1

Linking Identities to Interaction

\begin{tabular}{|c|c|}
\hline Role-immersion & Role-taking \\
\hline $\begin{array}{l}\text { Identity-related processes that focus us on } \\
\text { who we are in the role: } \\
\text { - Internal standards for role performance } \\
\text { O Using aspects of oneself in the work } \\
\text { role } \\
\text { Being engaged and fulfilled in the } \\
\text { work role }\end{array}$ & $\begin{array}{l}\text { Identity-related processes that focus us on } \\
\text { who our counterpart is: } \\
\text { - Role-taking } \\
\circ \text { Anticipating the other's needs } \\
\circ \text { Adjusting/Adapting to other's } \\
\text { behavior }\end{array}$ \\
\hline Intrinsic motivation & Perspective-taking \\
\hline
\end{tabular}


FIGURE 2

Theoretical Model

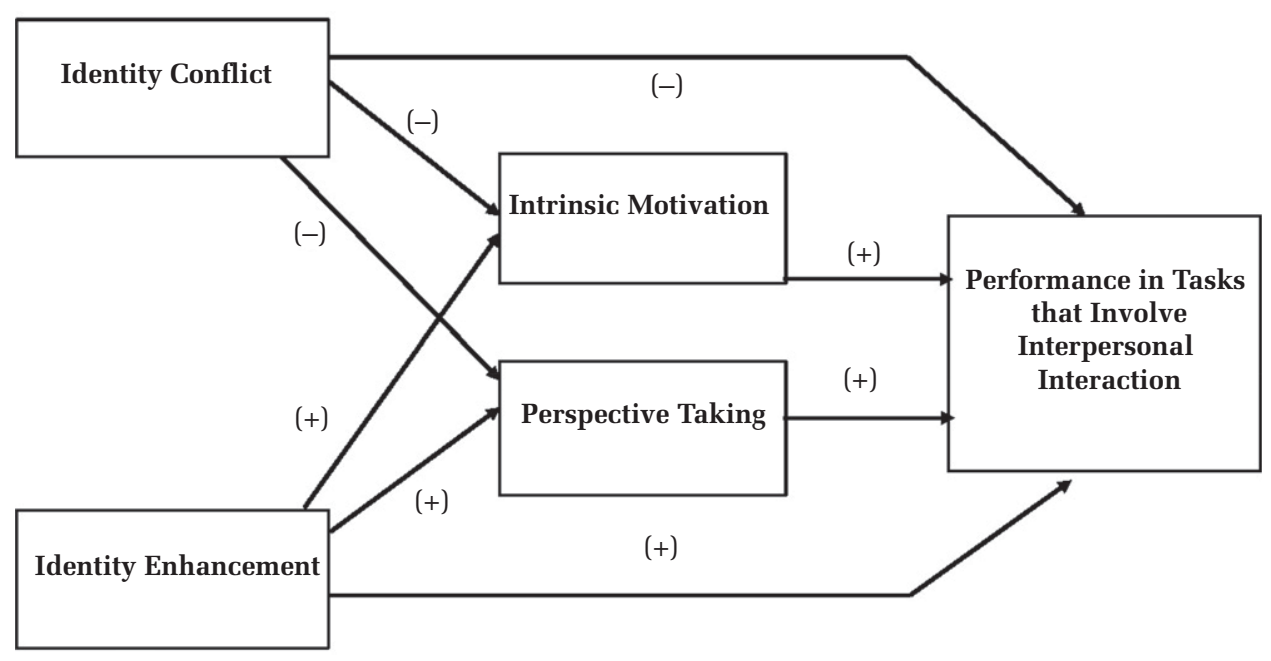

worlds. This may create distress and reduce our focus on our multiple work roles, reducing intrinsic motivation (Hirsh \& Kang, 2016; Kahn, 1990). Identity conflict may also reduce intrinsic motivation because it inhibits access to our various self-definitions, which limits our ability to use that self-knowledge in our work roles (Deci \& Ryan, 1995). The literature suggests that intrinsic motivation is associated with better work performance (Amabile, 1988; Deci \& Ryan, 2000; Gagné \& Deci, 2005). More specifically, work that involves interpersonal interaction, such as sales, may require the energy, effort, and persistence that come from intrinsic motivation in order to perform in the face of potential rejection and resistance (Grant, 2008; Spiro \& Weitz, 1990). Therefore, identity conflict is likely to have a negative effect on performance, in part because intrinsic motivation will be lower. Thus:

Hypothesis 3. Intrinsic motivation mediates the negative relationship between identity conflict and performance in a task that involves interpersonal interaction.

Identity enhancement. Identity enhancement is likely to amplify our intrinsic motivation, increasing performance. Identity enhancement may increase intrinsic motivation because more aspects of oneself are fully employed in the work and thus one is more fully immersed, which can be energizing and lead to more effort and persistence (Kahn, 1990; Rothbard, 2001). Identity enhancement is also likely to increase intrinsic motivation because it enables people to have greater cognitive access to their multiple workrole identities, which allows them to apply relevant self-knowledge to the work (Deci \& Ryan, 1995). As described above, greater intrinsic motivation is likely to positively influence performance in tasks that involve interpersonal interaction. Therefore, identity enhancement is likely to have a positive effect on performance, in part because intrinsic motivation will be greater. Thus:

Hypothesis 4. Intrinsic motivation mediates the positive relationship between identity enhancement and performance in a task that involves interpersonal interaction.

\section{Role-Taking: Multiple Identities, Perspective-Taking, and Performance}

Role identities also drive behavior in an interaction by focusing us on our interaction partners. In a role-based interaction, people not only define and express themselves in a role, they also engage in what identity scholars have termed "role-taking" (Mead, 1934; Turner, 1956). Role-taking is the process of "looking at or anticipating another's behavior by viewing it in the context of a role imputed to that other" (Turner, 1956: 316). That is, role-taking involves focusing on the other party's role and taking their perspective. Role-taking allows the focal person to maintain his or her own identities by "anticipating reactions" (Sluss et al., 2010:22) and adjusting his or her behavior to the counterpart's 
expectations and behaviors (Cast, 2004; Heimer \& Matsueda, 1994). ${ }^{3}$ The process of role-taking is consistent with the psychological literature on perspectivetaking, which defines perspective-taking as adopting the role of the other, stepping outside of one's own experience and imagining the emotions, perceptions, and motivations of another person from that person's point of view (Galinsky \& Moskowitz, 2000; Grant \& Berry, 2011; Williams, 2012).

Identity conflict. Identity conflict is likely to reduce perspective-taking, decreasing performance. Identity conflict entails a struggle to answer the question "who am I." This can make role-taking, i.e., understanding the other party's perspective, more challenging; if we do not know ourselves, then we do not know "who the other is." In addition, people may respond to identity conflict by disregarding important identities (Hugenberg \& Bodenhausen, 2004; Pratt \& Foreman, 2000; Vaughan, 1996) because it is associated with contradictory cognitions (Festinger, 1957). The experience of disregarding one's own multiple identities can lead us to more easily disregard (rather than take) another's perspective. Identity conflict can also create a sense of identity threat, which can narrow cognitions, limiting our ability to adopt another person's point of view (Petriglieri, 2011; Staw, Sandelands, \& Dutton, 1981).

Research has shown that perspective-taking is critical for performance in tasks that involve interpersonal interactions (Galinsky, Maddux, Gilin, \& White, 2008; Grant \& Berry, 2011; Parker \& Axtell, 2001) because it enables individuals to understand others' values and

\footnotetext{
${ }^{3}$ In addition to referring to putting oneself in another's shoes in the context of an interaction with a role partner, the term role-taking has also been used to describe taking on the role that the organization is sending through socialization, feedback, and learning (Katz \& Kahn, 1978; Sluss et al., 2010). Mead's (1934) original notion of roletaking includes both aspects-one in which we role-take in order to learn about our own roles, and another in which we role-take to anticipate other's reactions and adjust our behavior to facilitate interaction. Turner (1956), following Mead's symbolic interactionist approach, further developed the concept of role-taking by focusing on facilitating interaction. Both of these approaches are different from the use of the term "role-taking" in the leadermember exchange literature, which describes how the leader evaluates a subordinate's contribution to decide whether to invest in the relationship (e.g., Bauer \& Green, 1996). Because we are interested in an identity-based approach and in the outcomes of interactions, we use Turner's (1956) conceptualization, which focuses on roletaking as a way to facilitate interactions.
}

preferences and to anticipate others' behavior (Axtell, Parker, Holman, \& Totterdell, 2007; Davis, 1983). Therefore, the negative effects of identity conflict on performance are likely to occur in part because perspective-taking will be lower. Thus:

Hypothesis 5. Perspective-taking mediates the negative relationship between identity conflict and performance in a task that involves interpersonal interaction.

Identity enhancement. Identity enhancement is likely to amplify perspective-taking, increasing performance. Identity enhancement encourages greater role-taking because it allows us to define ourselves in a multi-dimensional, holistic way, which increases our ability to anticipate and recognize synergies among the expectations of our interaction partners. Identity enhancement may also increase perspectivetaking because it generates greater cognitive flexibility (Cheng et al., 2008; Gaither, Remedios, Sanchez, \& Sommers, 2015), which can create a mindset whereby one can take the perspective of the other party more easily and fluidly. In addition, identity enhancement increases perspective-taking because it generates a sense of psychological security, which can broaden our cognitions and create cognitive availability (Fiol, Pratt, \& O’Connor, 2009; Marcussen, 2006), which enables us to adopt another person's point of view. As described above, perspective-taking is likely to positively influence performance in interpersonal tasks. Therefore, the positive effects of identity enhancement on performance are likely to occur in part because perspective-taking will be greater. Thus:

Hypothesis 6. Perspective-taking mediates the positive relationship between identity enhancement and performance in a task that involves interpersonal interaction.

\section{OVERVIEW OF RESEARCH}

We use a multi-method approach to examine these relationships across two studies. In Study 1, a longitudinal field study of customer service representatives who simultaneously represent multiple product brands to customers, we examine the relationships among identity conflict and enhancement between the brands they represent, on the one hand, and objective sales performance over a fourmonth period, on the other. We also investigate intrinsic motivation and perspective-taking as mediators of these relationships. In Studies 2a and 2b, 
both between-subjects experimental studies, we constructively replicate and extend our findings using a moderation-of-process approach (Spencer, Zanna, \& Fong, 2005). Specifically, in Studies 2a and $2 \mathrm{~b}$, we jointly manipulate our independent variables and our process variables, intrinsic motivation, and perspective-taking, to test their effects on our dependent variable.

\section{STUDY 1}

In Study 1, we test our hypothesized model in a field setting, where employees' work-related identities have implications for objectively measured work performance. We test our model using a longitudinal dataset, matching survey and archival data collected in a customer service setting.

\section{Participants and Setting}

Participants were call center employees at a large company, 4C (pseudonym), that manages the customer service for credit cards associated with a number of well-known brands in the retail and financial services sectors among others. Customer service work is prototypical "people work" (Brotheridge \& Grandey, 2002; Hochschild, 1983). As with many call centers, the work goals of our customer service employees included both providing service and selling to customers. Our setting also provided an excellent opportunity to examine multiple work-role identities because each of the customer service employees worked with products, services, and customers across multiple brands, and, as such, they had the opportunity to identify with more than one brand (Hughes \& Ahearne, 2010). To confirm that brand identities were indeed salient, we first shadowed and then conducted interviews with employees in order to understand the nature of their work and their work-related identities. Consistent with research on employees' identification with brands, we found that employees in our setting identified with the brands they represented (e.g., "I am an ABC Clothing person"). Therefore, we examined conflict and enhancement between salient brand identities. For example, we examined whether being a representative for ABC Clothing was opposed to (or compatible with) being a representative for XYZ Bank.

\section{Procedure}

We gathered data from multiple sources, including survey, archival, and longitudinal performance data.
We first invited 1,487 customer service employees to take part in the survey. As an incentive, we entered participants into a lottery to receive a $\$ 10$ gift card, of which there were 50 cards on offer in total. Employees were given dedicated time off to take the survey, if they chose to participate. We received responses from 1,066 employees giving a response rate of 72 percent. During the survey, we asked participants to indicate the two brands they worked with the most. We then asked participants about their identification with the brands and the relationships (identity conflict and enhancement) between these brand identities. We also gathered survey data on our mediating variablesintrinsic motivation and perspective-taking. All survey measures for this study used a Likert-type $1=$ strongly disagree to $5=$ strongly agree response scale. We then matched these survey responses with archival measures of employees' sales performance collected in each of the four months after respondents had completed the survey. Last, using the firm's human resource records, we matched the survey responses with demographic characteristics. After listwise deletion of the data due to missing items and matching on control variables, we had a final sample of 763 participants, representing 49.5 percent of the original population contacted for participation.

\section{Measures}

Identity conflict and identity enhancement. We measured identity conflict and enhancement using two three-item scales adapted for brand identities. These items were adapted from existing measures of identity conflict and enhancement (Benet-Martinez \& Haritatos, 2005; Brook et al., 2008; Settles, 2004; Tiedje et al., 1990) and were pretested on other samples. ${ }^{4}$ To measure identity conflict and enhancement, we first asked participants to name the two brands they worked with the most. We then asked them to rate the extent to which they identified with each of these brands (described further below). Last, we asked them the extent to which they experienced conflict and enhancement between these brand identities. Participants read the following text: Think about your work representing both of the brands that you have selected ("Brand A" and "Brand B"). They then responded to the following items:

Identity conflict. The identity conflict items were: "Life would be easier if I represented only one of

\footnotetext{
${ }^{4}$ The items and factor analysis results are presented in Appendix A. Details on other pre-tests are available from the first author on request.
} 
these brands and not the other"; "Being a good representative for one of these brands interferes with being a good representative for the other brand"; and "I feel that representing one brand is opposed to representing the other brand." Cronbach's $\alpha$ is .72 for these three items.

Identity enhancement. The identity enhancement items were: "I am glad that I am a representative of both brands"; "I am a better representative of one brand because I am also a representative for the other brand"; "I appreciate being a representative for one brand because it helps me be a representative for the other brand." Cronbach's $\alpha$ is .70 for these three items.

Intrinsic motivation. We adapted Guay, Vallerand, and Blanchard's (2000) four-item measure of intrinsic motivation to the work context, replacing the phrase "this activity" with "this job." Participants were asked to respond to items such as "I work at this job because I think it is interesting." Cronbach's $\alpha$ is .92 for these four items.

Perspective-taking. We measured perspectivetaking based on a 4-item scale adapted to specifically measure the extent to which participants took on a customer's point of view (Williams, 2012; Williams \& Polman, 2015). Participants were asked to respond to items such as "When interacting with customers, I try to look at matters in terms of their personal concerns." Cronbach's $\alpha$ is .89 for these four items.

Sales performance. We were able to collect data on the number of sales each person made in a month for the four months after the administration of the survey. As described above, part of the employees' job was to sell additional products and services to customers during calls. Selling additional products and services is a common industry practice (Jasmand, Blazevic, \& de Ruyter, 2012). Sales were an important source of revenue for the organization and hence were valued by the organization as a measure of individual performance.

\section{Control Variables}

Average brand identification. Because we were conceptually interested in work-role identities rather than roles per se, we measured the degree to which employees' identified with the two brands they worked with the most (i.e., their most salient brand identities). We measured brand identification using 3 items for each brand. These items were adapted from Mael and Ashforth (1992). Specifically, we asked participants to respond to the following items: "When I talk about this brand, I usually say 'we' rather than 'they'”; "This brand's successes are my successes"; and "When someone praises this brand, it feels like a personal compliment." Cronbach's $\alpha$ 's for these two scales were .78 and .79, respectively. Given that these two brand identification scales were very highly correlated $(r=.83, p<.001)$, we averaged these two scales following Brook et al. (2008), and control for the average strength of identification with the two brands. The Cronbach's $\alpha$ for the combined scales is .90.

Demographic controls. As control variables in our analyses, we included several important individual characteristics that past research has suggested should be systematically related to performance. First, we included gender and race because these characteristics have been shown to influence performance in customer service and sales settings. This is often due to the demographic composition of the organization, poor diversity climates, or supervisor and customer biases (Hekman, Aquino, Owens, Mitchell, Schilpzand, \& Leavitt, 2010; Joshi, Liao, \& Jackson, 2006; McKay, Avery, \& Morris, 2008). Both race and gender were coded as dummy variables (White $=1$ and Nonwhite $=$ 0 ; Male $=1$ and Female $=0$ ). Second, we included tenure (measured as number of years) because studies show that the longer an employee has had experience in the same organization, the more likely he or she is to perform well (Ng \& Feldman, 2010; Sturman, 2003). Third, we included age because research shows that as employees get older, they may not only lose physical and cognitive skills, customers may also respond more negatively toward them (Sturman, 2003). Furthermore, we also included age-squared because several studies show that in addition to a linear negative effect on performance, age has nonlinear effects on performance as well (Avolio, Waldman, \& McDaniel, 1990; McEvoy \& Cascio, 1989; Ng \& Feldman, 2008; Sturman, 2003). Last, in addition to individual characteristics, we also included one contextual variable, the call center location. Our site had more than one location. Of the locations we studied, one site in particular was the only site located in a different state and was also the lowest performing. Therefore, to account for this difference, we included a dummy variable for that location.

Month. To account for monthly variation in our dependent variable (unit sales/month), we included dummy variables for months (the first month was the omitted category).

\section{Analysis}

We tested the relationships between identity conflict and enhancement, our mediator variables, and sales using multi-level models. For the sales 
analyses, we ran multi-level models nested within individual (because we had four months of sales performance data for each employee) and nested within supervisor (because some employees shared the same supervisor). For the analyses using intrinsic motivation and perspective-taking as the dependent variables, we nested within supervisor only. All multi-level models were run using the mixed command in STATA. Multi-level models are preferable where systematic within-level differences (i.e., within person repeated measures) might bias results if observations are assumed to be independent as in OLS (Kreft, Kreft, \& de Leeuw, 1998). To test the mediation hypotheses, we also used multi-level structural equation modeling (SEM) in MPlus (Muthén \& Muthén, 2012). This allows us to estimate the indirect effects in the mediation models and also accounts for the nested nature of our data (Preacher, Zhang, \& Zyphur, 2011; Preacher, Zyphur, \& Zhang, 2010).

To assess the appropriateness of this analytical strategy, we calculated the intraclass correlation coefficient, ICC(1), which measures how much variance in the outcome is accounted for by nesting measures within each person. ICC(1)s that are over .25 are considered a "large" effect (LeBreton \& Senter, 2008)-i.e., one-quarter or more of the variability in the outcome is due to systematic within-person differences across time. For sales performance, we tested whether we needed to run a three-level model, in which monthly sales were nested within individual, which in turn were nested within supervisor. In this model, the ICC(1) was .69 for individual and .002 for supervisor. However, we also examined whether it was important to nest within supervisor for our two mediator variables, perspective-taking and intrinsic motivation. The ICC (1) for supervisor was .09 for perspective-taking and .17 for intrinsic motivation. While not high, because there was some variation explained by the supervisor for the mediators, to be consistent we also included the supervisor level in our sales models. ${ }^{5}$

\footnotetext{
${ }^{5}$ Robustness checks: A Hausman test was not significant, suggesting a fixed effects model was not necessary and that a random effects model was appropriate. However, we also examined a model with supervisor fixed effects and found that our results were robust. We also aggregated our monthly sales variables to the average sales by individual and tested our hypotheses nesting by supervisor only and found that our results were robust. Results are available from the first author on request.
}

\section{Results}

Table 1 shows the means, standard deviations, and correlations for the variables analyzed in Study 1 . Table 2 shows the effects of our independent variables and mediators on sales performance. Table 3 shows the effects of our independent variables on our two mediators, intrinsic motivation, and perspective-taking. Figure 3 shows the findings for our SEM model.

Table 1 shows that there is a small negative correlation between identity conflict and enhancement $(r=-.21, p<.001)$. In Table 2, Model 1 shows the effects of the control variables. In Table 3, Models 1a and $1 \mathrm{~b}$ show the effects of the control variables. The subsequent models then show the effects of the relevant independent variables above and beyond the controls. An important control variable is average role identification (Brook et al., 2008). Table 2 shows that average work-role identification with the brands is positively related to performance (Model 1: $\beta=$ 2.69, $p=.06$ ), and Table 3 shows that it is positively and significantly related to intrinsic motivation (Model 1a: $\beta=.53, p<.001$ ) and perspective-taking (Model 1b: $\beta=.32, p<.001$ ). However, Tables 2 and 3 also show that the effects of identity conflict and enhancement on all three outcome variables hold above and beyond average role identification. ${ }^{6}$

Identity conflict and enhancement predict performance. As predicted by Hypothesis 1, Table 2 shows that identity conflict is significantly and negatively related to performance (Model 2: $\beta=-2.75$, $p<.05$ ). As predicted by Hypothesis 2 , identity enhancement is significantly and positively related to performance (Model 3: $\beta=3.20, p<.05$ ). Table 2 (Model 4) further shows that the effects of identity conflict and enhancement are also significant when controlling for one another. That is, the effect of one does not depend upon or eliminate the other, suggesting that the two constructs have distinct effects on performance. ${ }^{7}$

\footnotetext{
${ }^{6}$ The effects described below are robust to whether average role identification is included or excluded from the models. We also examined if average role identification moderated the effects of identity conflict and enhancement on sales performance and found no support for an interaction effect $\left(\beta_{\mathrm{confxID}}=1.07, p=.51 ; \beta_{\mathrm{enhXID}}=-1.59, p=.36\right)$.

${ }^{7}$ Because we theorized that identity conflict and enhancement are independent of one another, we also explored an interaction effect of the two variables on performance. We found no support for an interaction effect on sales performance $(\beta=-1.70, p=.20)$.
} 


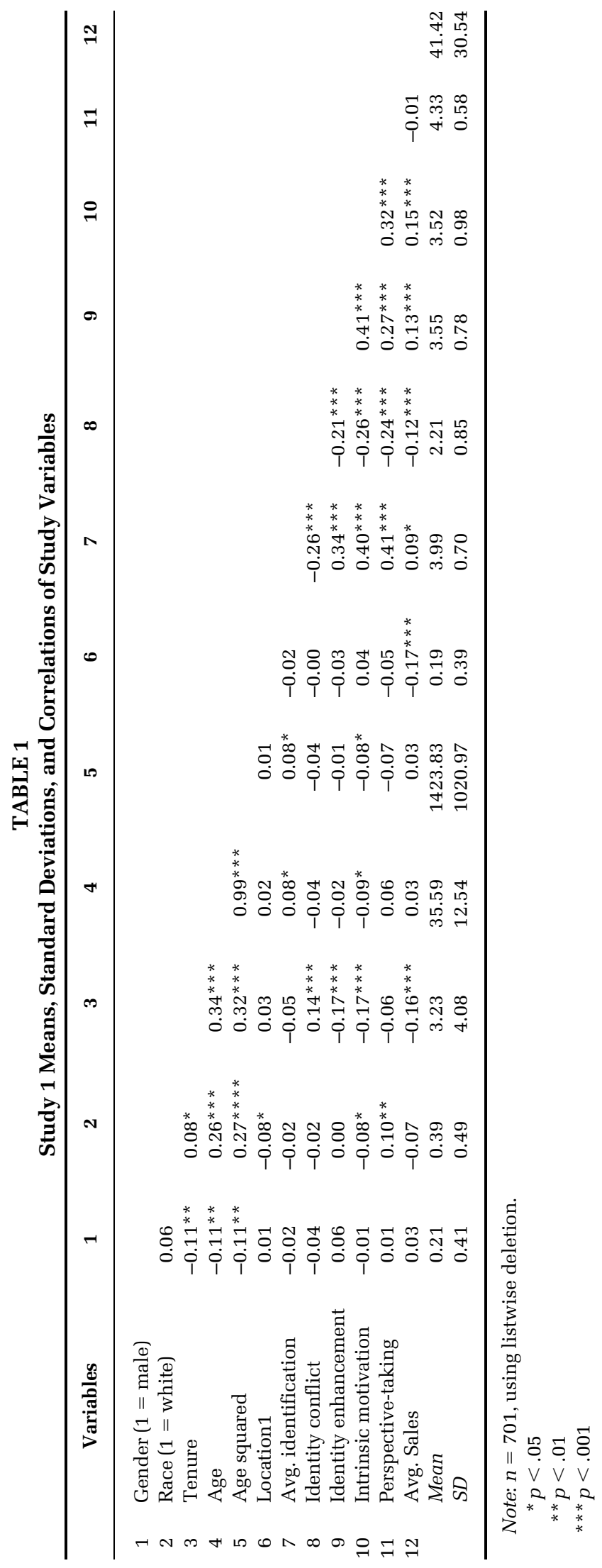




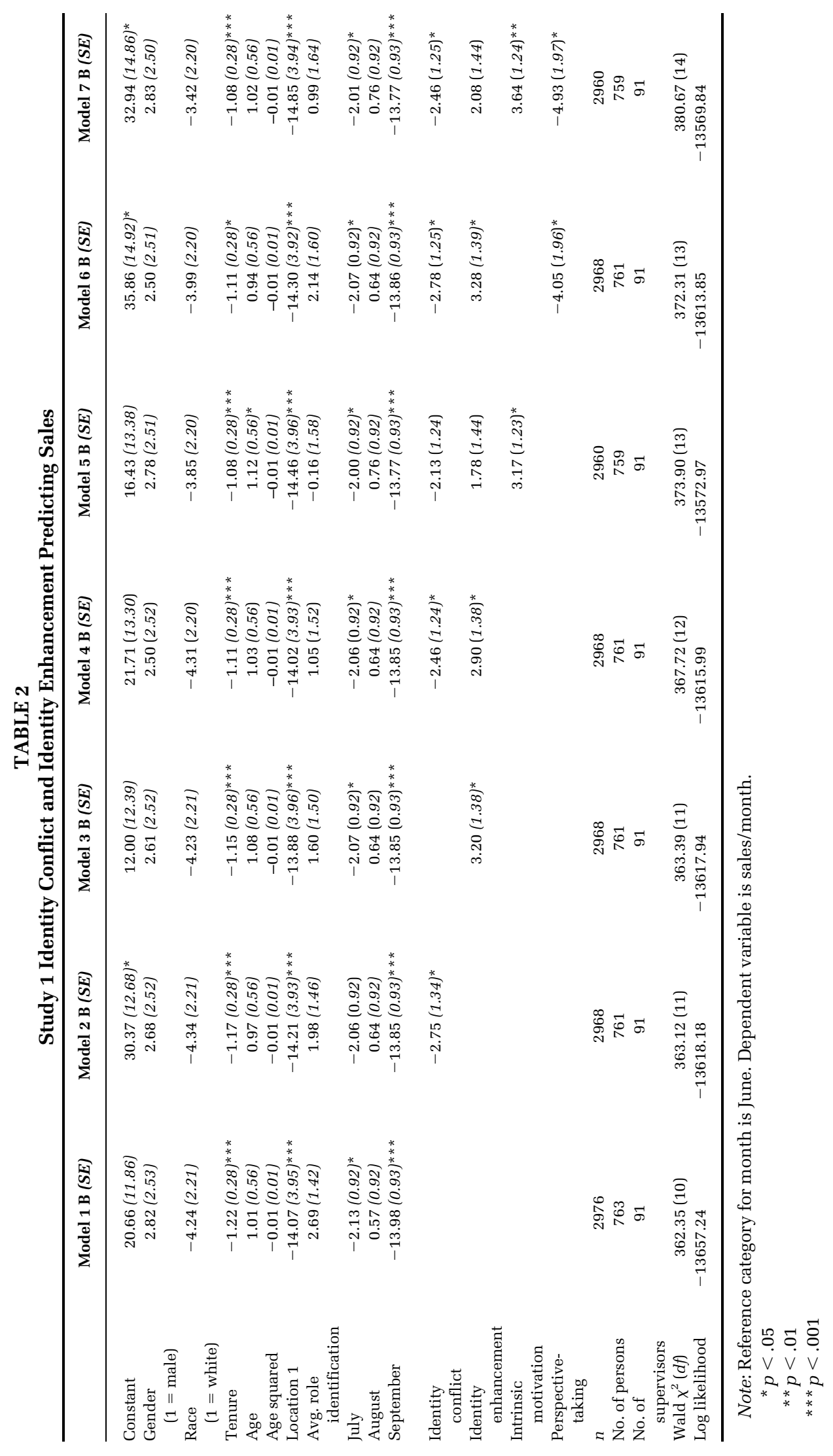




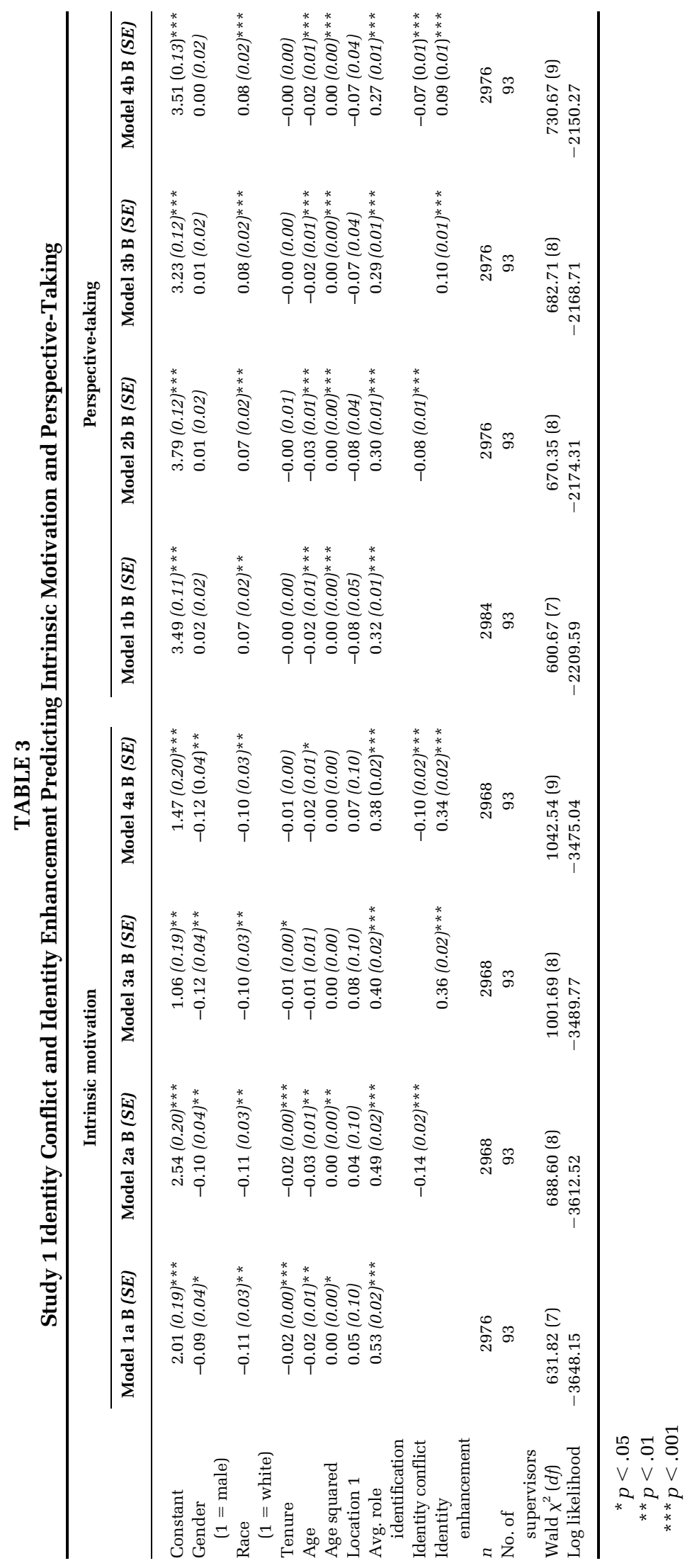


FIGURE 3

\section{Study 1 Results for Multilevel Structural Equation Model Predicting Sales Performance}

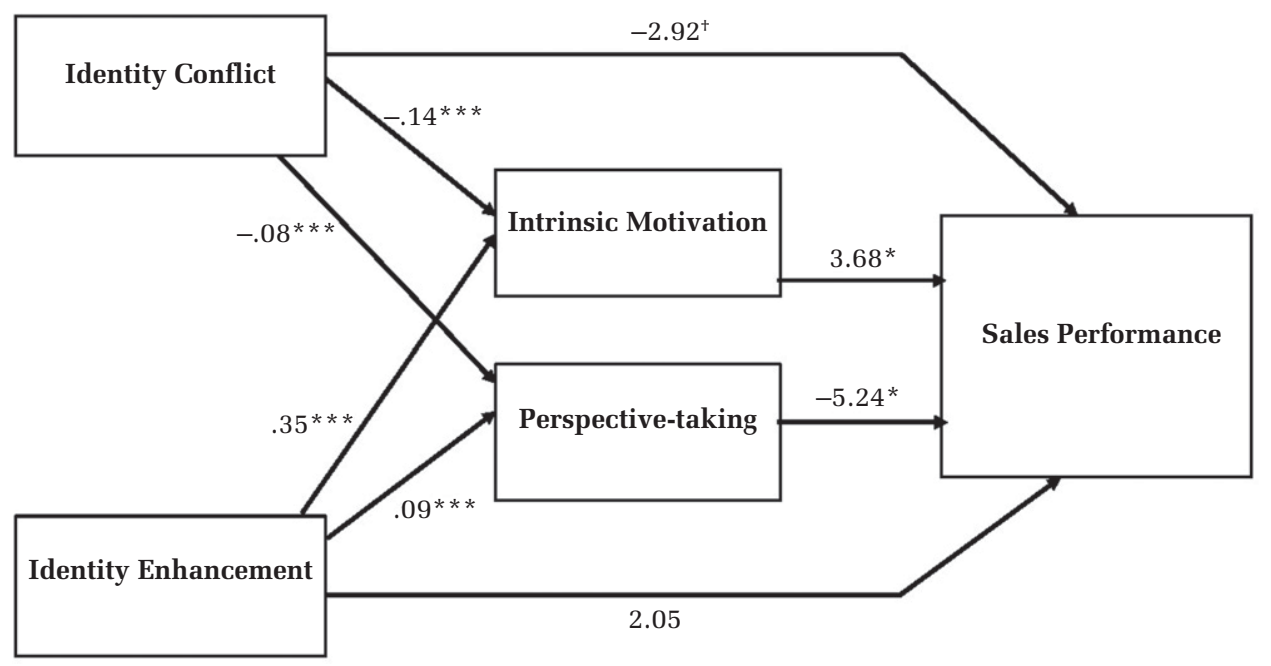

Notes: Coefficients for the direct effects presented in the figure above and the indirect effects presented below are from the multi-level SEM clustering by individual and by supervisor.

${ }^{+} p<.1$

${ }^{*} p<.05$

${ }^{* *} p<.01$

$* * * p<.001$; two-tailed tests.

Model fit statistics are: $\mathrm{CFI}=.98 ; \mathrm{RMSEA}=.07, p=.009 ; \mathrm{SRMR}_{\mathrm{W}}=.01 ; \mathrm{SRMR}_{\mathrm{B}}=.00$.

(1) Hypothesis 3: identity conflict $\rightarrow$ intrinsic motivation $\rightarrow$ performance: significant negative indirect effect. $(\beta=-.51, p<.05)$

(2) Hypothesis 4: identity enhancement $\rightarrow$ intrinsic motivation $\rightarrow$ performance: significant positive indirect effect. $(\beta=1.27, p<.05)$

(3) Hypothesis 5: identity conflict $\rightarrow$ perspective-taking $\rightarrow$ performance: significant negative indirect effect $(\beta=-.43, p=.05)$

(4) Hypothesis 6: identity enhancement $\rightarrow$ perspective-taking $\rightarrow$ performance: significant positive indirect effect. $(\beta=-.48, p<.05)$

\section{Identity conflict and performance mediated by} intrinsic motivation. Hypothesis 3 predicted that intrinsic motivation would mediate the relationship between identity conflict and performance. Consistent with Hypothesis 3, Table 3 shows that the relationship between identity conflict and intrinsic motivation is negative and significant (Model 2a: $\beta=-.14, p<.001$ ). Further, Table 2 shows that when intrinsic motivation is included as a predictor of sales, it is positive and significant (Model $5: \beta=3.17$, $p<.05$ ) and the effect of identity conflict on performance is no longer significant (Model $5: \beta=-2.13$, $p=$ n.s.). To test the mediation effect, we used multilevel structural equation modeling (SEM). The model fit the data well (CFI $=.98$; RMSEA $=.07, p=.15$; $\mathrm{SRMR}_{\mathrm{W}}=.01 ; \mathrm{SRMR}_{\mathrm{B}}=.00$ ). For the relationship between identity conflict and performance, the indirect effect through intrinsic motivation is: $\beta=-.51$, $p<.05$ (95\% CI $=-1.01$ to -.02$)$, supporting Hypothesis 3.

Identity enhancement and performance mediated by intrinsic motivation. Hypothesis 4 predicted that intrinsic motivation would mediate the relationship between identity enhancement and performance. Consistent with Hypothesis 4, Table 3 shows that the relationship between identity enhancement and intrinsic motivation is positive and significant (Model 3a: $\beta=.36, p<.001$ ). Further, Table 2 shows that when intrinsic motivation is included as a predictor of sales, the effect of identity enhancement is no longer significant (Model 5: $\beta=$ 1.78, $p=$ n.s.). To test the mediation, we used the same SEM model discussed above. For the relationship between identity enhancement and performance, the indirect effect through intrinsic motivation is: $\beta=1.27, p<.05$ (95\% C.I. $=.19$ to 2.36 ), supporting Hypothesis 4.

Identity conflict and performance mediated by perspective-taking. Hypothesis 5 predicted that perspective-taking would mediate the relationship between identity conflict and performance. Consistent with Hypothesis 5, Table 3 shows that the relationship between identity conflict and perspective-taking is negative and significant (Model 2b: $\beta=-.08, p<.001$ ). However, Table 2 shows that counter to the direction predicted, perspective-taking is significantly 
and negatively related to performance (Model 6: $\beta=-4.05, p<.05$ ). Moreover, when including perspective-taking in the model, the effect of identity conflict on performance is still significant and negative (Model 6: $\beta=-2.78, p<.05$ ). To test the mediation, we used the same SEM model discussed above. For the relationship between identity conflict and performance, the indirect effect through perspectivetaking is: $\beta=.43, p=.05,(95 \% \mathrm{CI}=.00$ to .86$)$. Thus, perspective-taking mediated this relationship, but not in the direction hypothesized in Hypothesis 5 due to the unexpected negative effect of perspective-taking on performance.

Identity enhancement and performance mediated by perspective-taking. Hypothesis 6 predicted that perspective-taking would mediate the relationship between identity enhancement and performance. Consistent with Hypothesis 6, Table 3 shows that the relationship between identity enhancement and perspective-taking is positive and significant (Model 3b: $\beta=.10, p<.001$ ). Table 2 shows that when perspective-taking is included as a predictor of sales performance, the effect of identity enhancement is still significant and positive (Model $6: \beta=3.28, p<.05$ ). To test the mediation, we used the same SEM model discussed above. For the relationship between identity enhancement and performance, the indirect effect through perspective-taking is: $\beta=-.48, p<.05$ (95\% $\mathrm{CI}=-.91$ to -.05 ). Thus, perspective-taking mediated this relationship, but not in the direction predicted by Hypothesis 6 due to the negative effect of perspectivetaking on performance.

\section{Discussion}

In a longitudinal field study of customer service representatives, we found that identity conflict and enhancement were significantly related to objective sales performance and these relationships were mediated by intrinsic motivation. The findings for perspective-taking, however, were more complex. Although perspective-taking statistically mediated these relationships, it was counter to the expected direction.

A strength of Study 1 is that we examined these relationships in a field setting using employees' workrole identities and objective sales performance that resulted from actual employee-customer interactions. We were also able to establish some causal inference because our performance data were collected after we measured our independent and mediator variables. Study 1 also provided a statistical test of mediation. We were also able to gain some theoretical insight from examining the intraindividual unit of analysis. Specifically, we found that while there was variation in monthly performance, the effects of identity conflict and enhancement on performance are persistent. This is theoretically interesting because it suggests that identity conflict and identity enhancement between work identities might be chronically salient. Moreover, these effects are persistent with brand identities, which we might presume are more ephemeral, suggesting that brands are chronic sources of work identification.

However, Study 1 also has some limitations. First, we were unable to disentangle the causal ordering among our independent and mediator variables because they were collected at the same time. ${ }^{8} \mathrm{Al}-$ though longitudinally separated, the causal relationship between our mediators and dependent variables could also be strengthened. Second, our measure of identity conflict and enhancement may not reflect the underlying values associated with brand identities. Last, the unexpected negative relationship between perspective-taking and performance also requires further investigation.

To address the above limitations, in Studies 2a and $2 \mathrm{~b}$ we conduct experiments using a betweensubjects design to isolate and better examine the mechanisms we find in the field study. We employ a moderation-of-process approach to constructively replicate and extend the findings (Spencer et al., 2005). The experimental moderation-of-process design provides evidence for a theoretically proposed psychological process by providing a test of the causal relationships between the independent variables and the dependent variables while simultaneously experimentally manipulating the proposed psychological process variable as a moderator. Spencer and colleagues (2005) argue that the moderation-of-process approach allows for stronger causal inference about a psychological process compared to statistical tests of measured mediation (Baron \& Kenny, 1986) because both the independent variable and the theoretically proposed process variables are manipulated simultaneously (see

\footnotetext{
${ }^{8}$ To address this limitation, we also conducted a series of studies using the experimental causal chain design (Spencer et al., 2005). This allowed us to test the causal effects of identity conflict and enhancement on the mediators, intrinsic motivation, and perspective-taking. Consistent with the results in Study 1, we find support for the causal effect of the independent variables on the mediators. Results are available from the first author.
} 
Lount, Sheldon, Rink, \& Phillips, 2015 and Loyd, Wang, Phillips, \& Lount, 2013 for recent examples). Following this approach, we manipulate the independent variables, identity conflict, and enhancement, and the theoretically proposed mediator variables, intrinsic motivation (in Study 2a) and perspective-taking (in Study 2b), and show their joint effects on intention to sell, the dependent variable. Thus, Study 2a causally tests the proposed psychological process via intrinsic motivation (Hypotheses 3 and 4) and Study 2b causally tests the proposed psychological process via perspective-taking (Hypotheses 5 and 6).

\section{Study 2a: Effects of Identity Conflict and Enhancement and Intrinsic Motivation on Sales}

In Study 2a, we manipulated the relationship between identities (i.e., conflict vs. enhancement) and intrinsic motivation to examine their joint effects on intention to sell.

Sample. Participants were 1002 adults recruited through the Amazon Mechanical Turk (MTurk) service (Buhrmester, Kwang, \& Gosling, 2011). MTurk workers were a suitable sample for our study because they are working adults likely to be able to understand and identify with situations in which people hold multiple work roles. For instance, people who hold jobs on MTurk also often hold a variety of other full-time and part-time jobs, such as professional, managerial, sales, and service jobs (Berinsky, Huber, \& Lenz, 2012; Casler, Bickel, \& Hackett, 2013; Goodman, Cryder, \& Cheema, 2013). In this sample, the average age was 37 years $(S D=$ 12.52), 54.9 percent were female, and all were located in the United States. Participants were paid $\$ 1.50$ for their participation.

Procedure. We used a $2 \times 2$ between-subjects design. The first factor was the independent variable: Identity conflict vs. Identity enhancement. The second factor was the theoretically proposed process variable: Intrinsic motivation (present vs. absent). Participants were randomly assigned to one of four conditions: identity conflict/intrinsic motivation; identity enhancement/intrinsic motivation; identity conflict/no intrinsic motivation; and identity enhancement/no intrinsic motivation.

Participants were presented with a general customer service scenario similar to the setting we examined in Study 1 in which they were asked to imagine that they were customer service representatives in a call center. They were told they represented two brands that were associated with values they personally held and that they used these brands themselves and identified strongly with them, as the literature suggests that values are a basis of identity conflict and enhancement (Benet-Martinez \& Haritatos, 2005; Pratt \& Foreman, 2000). All participants were told that "people have many values that are important to them, several of which are universally shared. Specifically, studies show that people value (1) having fun and enjoying life and (2) helping other people and contributing to society." They were then asked to write two sentences explaining how each of these values was important to them and played out in their lives (Grant \& Rothbard, 2013). They also answered questions about how much they identified with each of these values. All participants were then provided with the following customer service scenario:

Please imagine you are a customer service representative in a call center. You represent two clothing brands, each of which is associated with the values you described previously. Your job is to resolve customer problems and sell these brands. Brand EnjoyingLife is a stylish clothing line that provides customers with enjoyable, fun options. This brand is associated with your value of having fun and enjoying life. Brand HelpingHand is a socially conscious clothing line that donates a portion of profits to charitable causes. This brand is associated with your value of helping people and contributing to society. You personally wear and strongly identify with both brands because they are associated with values that are important to you.

We then manipulated whether they perceived these identities as conflicting or enhancing and conducted a short manipulation check. Next, we manipulated whether they were intrinsically motivated or not and conducted a short manipulation check. We then described a typical employeecustomer interaction in a call center setting, telling participants: "A customer is calling with an issue on one of the brands. You have the opportunity to resolve the problem and to sell the customer additional clothing." We then asked them about their intention to sell additional items of clothing.

Identity conflict and enhancement manipulations. We manipulated whether participants experienced the relationship between their two work-role identities (representing Brand EnjoyingLife and Brand HelpingHand) as conflicting [enhancing] using the following text accompanied by a visual representation (see Appendix B): 
Although [Further] the values of (a) having fun and enjoying life and (b) helping others and contributing to society are both important to you, [and] you find they conflict with [enhance] one another greatly. Indeed, as a customer service representative, you find that identifying with EnjoyingLife and HelpingHand can be highly conflicting [enhancing] making it very difficult [easy] to represent both brands. Providing customers with EnjoyingLife products greatly interferes with [facilitates] providing them with HelpingHand products, and vice versa, because you find that these two values strongly oppose [complement] one another.

Intrinsic motivation. The intrinsic motivation manipulation followed the identity conflict and enhancement manipulation. We manipulated intrinsic motivation by telling participants to:

Recall a time when you found your work to be highly interesting [not at all interesting]. Imagine this job is similar and that you find being a customer service representative for brands EnjoyingLife and HelpingHand to be highly interesting [not at all interesting] and very stimulating [boring].

Last, participants were presented with the following reminder that combined both manipulations:

Given your view that identifying with both brands is highly conflicting and difficult [enhancing and easy] and the job is highly [not at all] interesting and stimulating [boring], please imagine what you would do in the following situation as the customer service representative.

\section{Measures}

Manipulation checks. We measured identity conflict and enhancement with a single item each: "My identity as a representative for brand EnjoyingLife highly conflicts with [enhances] my identity as a representative for brand HelpingHand." Intrinsic motivation and no intrinsic motivation were also measured with a single item each: "Being a customer service representative for brands EnjoyingLife and HelpingHand is highly [not at all] interesting and very stimulating [boring]." We used a five-point Likert scale $(1=$ strongly disagree, $5=$ strongly agree).

Dependent variable. Intention to sell was measured with the item: "How likely are you to try to sell the customer additional clothing?" (1 = highly unlikely to $7=$ highly likely). We standardized this variable for ease of interpretation of the results.

\section{Results}

Manipulation checks. The manipulation check showed that participants in the identity conflict and enhancement conditions responded as expected to the identity conflict $\left(\mathrm{F}_{3,998}=144.02, p<.001\right)$ and enhancement $\left(\mathrm{F}_{3,998}=36.19, p<.001\right)$ manipulations, respectively. Likewise, participants in the intrinsic motivation and no intrinsic motivation conditions responded as expected to the intrinsic motivation $\left(\mathrm{F}_{3,998}=230.17, p<.001\right)$ and no intrinsic motivation $\left(\mathrm{F}_{3,998}=150.57, p<.001\right)$ manipulations, respectively.

The effects of identity conflict, enhancement, and intrinsic motivation on sales. An overall ANOVA showed that means of intention to sell were significantly different by experimental condition $\left(\mathrm{F}_{3,998}=27.78, p<.001\right)$ (see Figure 4). A $2 \times 2$ univariate ANOVA further showed the main effects of the independent variables, conflict/enhancement $\left(F_{1}, 998=15.54, p=<.001\right)$ and the process variable, intrinsic motivation $\left(\mathrm{F}_{1,998}=59.20, p<.001\right)$ as well as their interaction term $\left(\mathrm{F}_{1,998}=6.98, p<.01\right)$. To test the moderation-of-process approach, we examined the hypothesized relationships using planned comparisons.

For identity conflict, the proposed causal process was that conflict should decrease intrinsic motivation, which should, in turn, decrease sales (Hypothesis 3). Thus, in the moderation-of-process approach, adding intrinsic motivation should eliminate the negative effect of identity conflict on sales. As expected, for those in the identity conflict condition, when we added intrinsic motivation they reported greater intention to sell compared to when intrinsic motivation was not present (Mean Conflict/IM $=.19>$ Mean Conflict $/$ NotIM $=-.44, t(998)=7.12, p<.001)$, indicating that the negative effect of identity conflict on sales was eliminated (see Figure 4).

For identity enhancement, the proposed causal process was that enhancement should increase intrinsic motivation, which should, in turn, increase sales (Hypothesis 4). Thus, in the moderation-ofprocess approach, removing intrinsic motivation should eliminate the positive effect of identity enhancement on sales. As expected, for those in the identity enhancement condition, when we removed intrinsic motivation they reported lower intention to sell compared to when intrinsic motivation was present $\left(\right.$ Mean $_{\mathrm{Enh} / \mathrm{NotIM}}=-.04<\mathrm{Mean}_{\mathrm{Enh} / \mathrm{IM}}=.27, t$ $(998)=3.67, p<.001)$, indicating that the positive effect of identity enhancement on sales was eliminated (see Figure 4). Overall, those with identity 
FIGURE 4

\section{Study 2a: The Effects of Identity Conflict and Enhancement with Intrinsic Motivation on Sales}

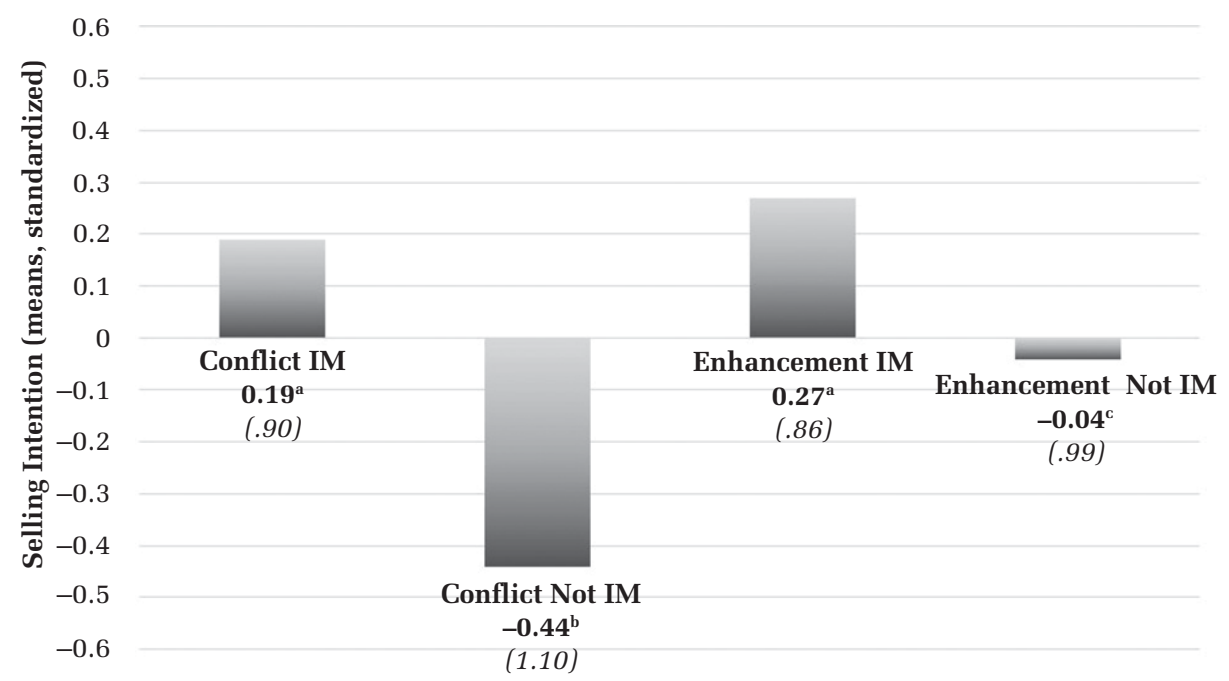

Note: Standardized means are in bold. Standard deviations are in parentheses. Means that do not share a superscript differ at $p<.05$.

conflict exhibited lower intention to sell than those with identity enhancement when intrinsic motivation was not present, $t(998)=-4.61, p<.001$, but not when intrinsic motivation was present, $t(998)=-.93, p=.35$ (see Figure 4).

Discussion. Study 2a complements Study 1 by establishing the causal relationship between identity conflict and enhancement, on the one hand, and sales, on the other, and the role of intrinsic motivation in the process. Specifically, we observe that the negative effect of identity conflict is diminished when intrinsic motivation is present and the positive effect of identity enhancement is diminished when intrinsic motivation is absent.

\section{Study $2 b$ Effects of Identity Conflict and Enhancement and Perspective-Taking on Sales}

In Study 2b, we manipulated the relationship between identities (i.e., conflict vs. enhancement) and perspective-taking to examine their joint effects on intention to sell.

Sample. Participants were 795 adults recruited through Amazon MTurk. Their average age was 35 years $(S D=10.87), 51.7 \%$ were female, and all were located in the United States. Participants were paid $\$ 1.50$ for their participation.

Procedure. We used a $2 \times 2$ between-subjects design as in Study 2a. The first factor was the independent variable: Identity conflict vs. Identity enhancement. The second factor was the theoretically proposed process variable: Perspective-taking (present vs. absent). Participants were randomly assigned to one of four conditions: identity conflict/ perspective-taking; identity enhancement/perspectivetaking; identity conflict/no perspective-taking; and identity enhancement/no perspective-taking. We used the same procedure and manipulations as described above in Study 2a. The only difference was that participants read manipulations regarding perspective-taking rather than intrinsic motivation.

The perspective-taking manipulation followed the conflict and enhancement manipulation. We manipulated perspective-taking by telling participants to:

Recall a time when you found it very important to take another person's [your own] perspective at work, rather than your own [another person's]. Imagine this job is similar and that as a customer service representative for brands EnjoyingLife and HelpingHand, you prefer to take your customer's [own] perspective. In other words, you [don't] put yourself in their shoes.

Last, participants were presented with the following reminder that combined both manipulations:

Given your view that identifying with both brands is highly conflicting and difficult [enhancing and easy] but [and] that you prefer to take the customer's [your own] perspective rather than your own [the customer's], please imagine what you would do in the following situation as the customer service representative. 


\section{Measures}

Manipulation checks. As in Study 2a, we measured identity conflict and enhancement with a single item each: "My identity as a representative for brand EnjoyingLife highly conflicts with [enhances] my identity as a representative for brand HelpingHand." Perspective-taking and no perspective-taking were also measured with a single item each: "As a customer service representative for brands EnjoyingLife and HelpingHand, you prefer to take the customer's [your own] perspective [instead of the customer's perspective]." For all items, we used a five-point Likert scale $(1=$ strongly disagree, $5=$ strongly agree).

Dependent variable. Intention to sell was measured with the item: "How likely are you to try to sell the customer additional clothing?" $(1=$ highly unlikely to $7=$ highly likely). We standardized this variable for ease of interpretation of the results.

\section{Results}

Manipulation check. The manipulation check showed that participants in the identity conflict and enhancement conditions responded as expected to the identity conflict $\left(\mathrm{F}_{3,791}=111.9, p<.001\right)$ and enhancement $\left(\mathrm{F}_{3,791}=31.46, p<.001\right)$ manipulations, respectively. Likewise, participants in the perspective-taking and no perspective-taking conditions responded as expected to the perspectivetaking $\left(\mathrm{F}_{3,791}=73.68, p<.001\right)$ and no perspectivetaking $\left(\mathrm{F}_{3,791}=55.57, p<.001\right)$ manipulations, respectively.

The effects of identity conflict, enhancement, and perspective-taking on sales. An overall ANOVA showed that the means of intention to sell were significantly different by experimental condition $\left(\mathrm{F}_{3,791}=4.41, p<.05\right)$. A $2 \times 2$ univariate ANOVA further showed the main effects of the independent variables, identity conflict/enhancement $\left(\mathrm{F}_{1,791}=5.56, p<.05\right)$, and the process variable, perspective-taking $\left(\mathrm{F}_{1,791}=2.28, p=n s\right)$, and their interaction term $\left(\mathrm{F}_{1,791}=5.91, p<.05\right)$. To test the moderation-of-process approach, we examined the hypothesized relationships using planned comparisons.

For identity conflict, the proposed causal process was that conflict should decrease perspective-taking, which should, in turn, decrease sales (Hypothesis 5). However, we found in our field study (Study 1) that perspective-taking had a negative relationship with sales in our customer service context. Therefore, if consistent with Study 1, identity conflict should reduce perspectivetaking, which should increase sales. Thus, in the moderation-of-process approach, adding perspectivetaking should amplify, rather than eliminate, the negative effect of identity conflict on sales. However, for those in the identity conflict condition, intention to sell was not significantly different when perspective-taking was present vs. absent $\left(\right.$ Mean $_{\text {Conflict } / \mathrm{PT}}=-.05$ vs. Mean Conflict $/ \mathrm{NotPT}=-.11$, $t(791)=.66, p=$ n.s.), indicating that the negative effect of conflict on sales was neither amplified nor eliminated by the presence of perspective-taking (see Figure 5).

For identity enhancement, the proposed causal process was that enhancement should increase perspective-taking, which should in turn increase sales (Hypothesis 6). However, if consistent with the negative relationship between perspective-taking and sales (Study 1), identity enhancement should increase perspectivetaking, which should decrease sales. Thus, in the moderation-of-process approach, removing perspective-taking should amplify, rather than eliminate, the positive effect of identity enhancement on sales. In this study, counter to our initial hypothesis, but consistent with Study 1, for those in the identity enhancement condition, intention to sell was significantly higher when perspective-taking was absent vs. present $\left(\right.$ Mean $_{\mathrm{Enh} / \mathrm{NotPT}}=.22>\mathrm{Mean}_{\mathrm{Enh} / \mathrm{PT}}=-.05, t(791)=$ $-2.76, p<.05$ ), indicating that the positive effect of enhancement on sales was amplified (see Figure 5). Overall, those in the identity enhancement condition showed greater intention to sell than those with identity conflict when perspectivetaking was absent, $t(791)=-3.32, p=.001$ but not when perspective-taking was present, $t(791)=0.05$, $p=$ n.s. (see Figure 5).

Discussion. Study 2b complements Study 1 by examining whether perspective-taking explains the relationship between identity conflict and enhancement, on the one hand, and sales, on the other. In Study 2b, we did not find evidence that perspective-taking influenced the relationship between identity conflict and sales (Hypothesis 5). This could be because the effects of identity conflict are complex with regard to perspectivetaking. For instance, it may be that at times people respond to psychological conflict in integrative ways leading to some cognitive benefits (Benet-Martinez, 
FIGURE 5

\section{Study 2b: The Effect of Identity Conflict and Enhancement with Perspective-Taking on Sales}

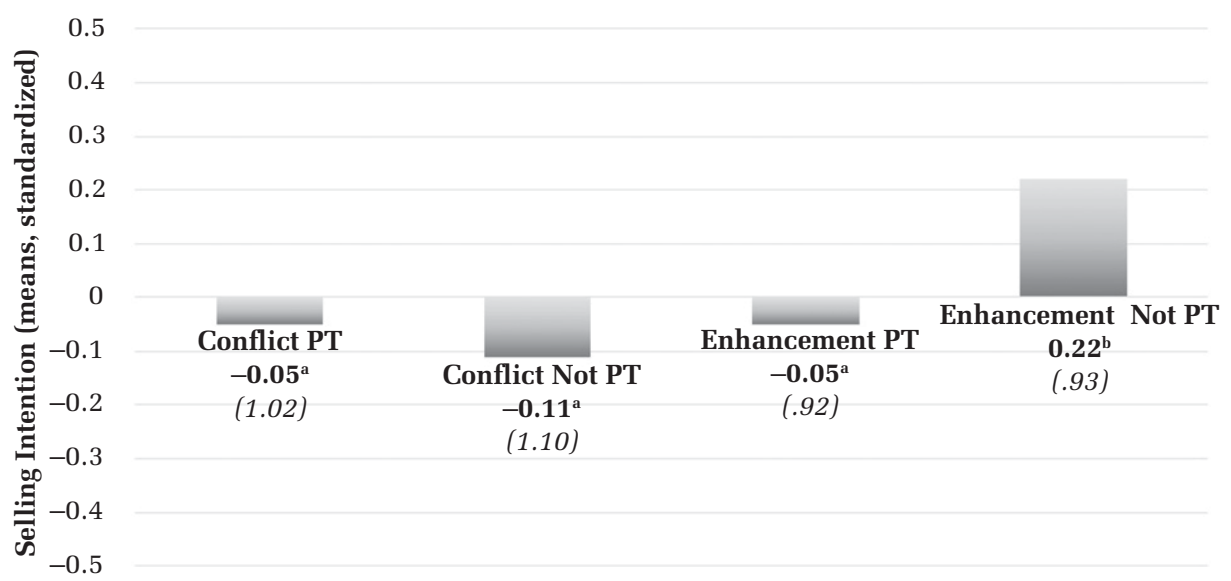

Note: Standardized means are in bold. Standard deviations are in parentheses. Means that do not share a superscript differ at $p<.05$.

Lee, \& Leu, 2006; George \& Zhou, 2002), which may weaken the influence of perspective-taking on the relationship between identity conflict and sales. By contrast, counter to Hypothesis 6, but consistent with the findings of Study 1, we observe that perspective-taking dampens the positive relationship between identity enhancement and sales. Overall, Study $2 \mathrm{~b}$ shows that the role of perspective-taking differs depending on whether one is examining identity conflict or identity enhancement. This highlights the value of examining both identity conflict and enhancement separately, suggesting that they are not simply opposites of one another and the absence of conflict is not the same as the presence of enhancement.

The fact that the negative effect of perspectivetaking on selling that we found in Study 1 was partially replicated in Study $2 \mathrm{~b}$ prompted us to return to the literature to better understand this finding. The bulk of the literature suggests that perspective-taking will lead to improved outcomes (Axtell et al., 2007; Falk \& Johnson, 1977; Galinsky et al., 2008; Marsh, Serafica, \& Barenboim, 1980; Parker \& Axtell, 2001; Russell \& Kuhnert, 1993) because it enables people to anticipate others' concerns (Davis, 1983; Williams, 2012). However, some prior evidence for a negative relationship between perspectivetaking and performance has found that being too other-oriented can be detrimental to individual performance in some types of tasks (Amanatullah, Morris, \& Curhan, 2008; Curhan, Neale, Ross, \& Rosencranz-Engelmann, 2008; Gelfand, Major,
Raver, Nishii, \& O’Brien, 2006). For instance, salespeople who can put themselves in another's shoes often sell less to customers in part because they want to avoid hurting them (Rotemberg, 2010). Thus, perspective-taking may have had a negative effect on performance in our context because ironically it sensitizes one too much to customers' needs.

\section{GENERAL DISCUSSION}

Across multiple studies, using both longitudinal field data and experimental data, we find that identity conflict and enhancement within people can affect performance deriving from employee-customer interactions. Consistent with our theorizing, we find that identity conflict and enhancement affect both roleimmersion (i.e., intrinsic motivation) and role-taking (i.e., perspective-taking) processes. Furthermore, intrinsic motivation mediates the relationship between identity conflict and enhancement, on the one hand, and performance, on the other. However, perspectivetaking does not mediate these relationships in the expected direction.

\section{Contributions}

We make several theoretical contributions. First, current research on identity has largely focused on the salience of one identity at a time as a guide for individual behavior (Stryker \& Serpe, 1982; Tajfel \& Turner, 1987), overlooking the fact that people experience multiple identities, which can operate 
simultaneously. We build on and extend research on multiple identities (Ashforth \& Johnson, 2001; George \& Chattopadhyay, 2005; Thoits, 1983) by studying relationships of conflict and enhancement between identities. We show that identity conflict and enhancement are predictive of performance, controlling for the level of identification that may exist. Thus, our paper demonstrates that considering relationships among identities adds value beyond examining levels of identification alone (Lipponen et al., 2005; Tadmor et al., 2009). Examining relationships among identities provides a new lens through which we can understand the effects of multiple identities on organizationally relevant outcomes.

Second, we contribute to research on multiple identities by examining identity enhancement as a construct in its own right. Existing research has largely examined identity conflict (Ashforth et al., 2008; Horton et al., 2014) and conceptualized it as the opposite of enhancement (Brook et al., 2008; Pratt \& Foreman, 2000). However, related work on multiple roles and nascent theoretical work on multiple identities argue that scholars should view identity enhancement and conflict as distinct constructs (Dutton et al., 2010; Ramarajan, 2014; Rothbard, 2001; Rothbard \& Ramarajan, 2009). Our findings support the idea that identity conflict and enhancement are worth investigating separately as they have independent effects on intrinsic motivation, perspective-taking, and performance. Both our field and experimental studies demonstrate the distinct and independent effects of identity conflict and enhancement in different ways. First, in our field study we tested the effects of both and found that the effects of one are present controlling for the other. This suggests that identity conflict and enhancement are not mere opposites of one another because including one does not eliminate the effect of the other. Second, in our experimental studies, we observed that the absence of identity conflict is not the same as the presence of identity enhancement. For example, in Study $2 b$, we observed asymmetric results for the role of perspective-taking such that the positive effect of identity enhancement on sales was diminished by perspective-taking, while the negative effect of identity conflict was not affected. Taken together, the above results indicate that identity conflict and enhancement are distinct levers and each should be examined in its own right. The unique effects of identity conflict and enhancement suggest that for some organizational phenomena identity conflict might be more relevant than identity enhancement and vice versa.

The independence of identity conflict and enhancement also raises the question of whether they have joint effects. Indeed, the presence of both high identity conflict and enhancement may most resemble the experience of ambivalence with regard to relationships among multiple identities. Research on ambivalence suggests that while for the most part psychological conflict tends to be negative, there are specific situations in which it can have a positive effect on outcomes such as creativity (Ashforth, Rogers, Pratt, \& Pradies, 2014; Fong, 2006; Rothman \& Melwani, 2016).Therefore, we ran an additional experimental study examining the effects of identity conflict and enhancement on intention to sell and included a condition representing the presence of both identity conflict and enhancement in which we told participants that they found their identities to be both conflicting and enhancing (see Appendix C). In this study, we found a significant overall effect $\left(\mathrm{F}_{2,597}=4.40, p<\right.$ .05) such that those in the identity enhancement condition intended to sell significantly more than those in both the identity conflict $(t=2.48, p<.05)$ and the joint identity conflict and enhancement conditions $(t=2.63, p<.01)$. However, there was no difference between the identity conflict and the joint identity conflict and enhancement conditions $(t=$ $.24, p=.81$ ). This suggests that identity enhancement alone has the most positive effect on performance. While our results are consistent with the idea that there are often negative effects of ambivalence, future work should consider when the presence of both identity conflict and enhancement may be positive.

Third, our findings demonstrate that the psychological experience of multiple identities shapes how we perform in tasks that involve interpersonal interaction. This is important because it takes the effects of multiple identities beyond individually focused outcomes such as well-being (Brook et al., 2008) and individual creativity (Cheng et al., 2008) to interdependent tasks in organizations. Returning to ideas of role-immersion (Burke \& Reitzes, 1991; Kahn, 1990) and roletaking (Cast, 2004; Turner, 1956) embedded in identity theory (Stryker \& Burke, 2000) and symbolic interactionism (Mead, 1934), we proposed and tested two paths that provide important new ways of conceptualizing the effects of multiple identities on performance in tasks that involve interpersonal interaction. 


\section{Limitations and Future Directions}

In this research, we find largely consistent effects using multiple methods and studies. Although each individual study has limitations, some of which we noted in the discussion of each study, it is important to consider the studies as a set (McGrath, 1981). Consistent with this approach, we designed our studies so the weaknesses in one were offset by the strengths of another. Study 1 is a longitudinal field study with objective work performance as a dependent variable. It also provides insight into relationships between employees' actual experience of conflict and enhancement between work-role identities, on the one hand, and performance in a task that involves employee-customer interactions, on the other. Study 1 also provides a statistical test of the mediating mechanisms we proposed. However, Study 1 does not provide causal evidence of the relationships between our independent variables and mediators. Although we controlled for important characteristics that prior research has suggested should relate to performance, Study 1 may also be subject to omitted variable bias. Further, although our measure of identity conflict and enhancement in Study 1 is adapted from existing work (Benet-Martinez \& Haritatos, 2005; Brook et al., 2008; Settles, 2004), it may not reflect the underlying values associated with particular identities.

To address these issues, we designed two experimental studies (2a and 2b). These experiments use a moderation-of-process approach (Spencer et al., 2005) to demonstrate the causal influence of identity conflict/enhancement on the dependent variable via the proposed mediators. Moreover, because of random assignment, these experiments should be less subject to omitted variable bias. In addition, our manipulation of identity conflict/ enhancement creates a situation in which participants have to sell two products that each represent personally endorsed values, improving on our survey items from Study 1. Further, our dependent variable in the experiments, intention to sell, helps us isolate the influence of the focal participant experiencing identity conflict and enhancement, whereas the objective sales measure from the field data is the result of an interaction between both the representative and the customer.

Our findings regarding the effects of perspectivetaking merit discussion. Counter to our hypotheses, we found a negative effect of perspective-taking on performance in our field study (Study 1). However, the results of the lab study (Study 2b) were more equivocal. Consistent with Study 1, perspectivetaking dampened the positive effect of identity enhancement on performance, however, perspective-taking did not have an effect on the relationship between identity conflict and performance. This pattern may be because in our context perspective-taking ironically sensitizes one too much to customers' needs (Amanatullah et al., 2008; Gelfand et al., 2006; Rotemberg, 2010). Future work should examine these relationships further.

Our findings suggest several important directions for future research. First, future work should investigate the effects of identity conflict and enhancement in more depth. With regard to identity conflict in particular, people may respond in a variety of ways. For instance, people may prioritize one primary identity, compartmentalize identities, or integrate them in response to conflict (Pratt \& Foreman, 2000). Future work should investigate the conditions under which these different reactions to identity conflict occur and when identity conflict has positive vs. negative effects. While we did not find evidence of an interaction effect between identity conflict and enhancement in our field study and thus did not pursue this in the lab studies, it remains an open question. Future work should also investigate whether identity conflict and enhancement operate through different mechanisms than the role-immersion and role-taking paths we examined here, including other mechanisms such as integrative complexity and learning. Moreover, in this study we only examined conflict and enhancement between two identities. When we extend this to more identities, the effects of conflict and enhancement may become more complex (Ramarajan, 2014; Ramarajan, Berger, \& Greenspan, 2017). For example, some identity pairs could be conflicting and others enhancing. Future work should examine relationships among more than two identities.

Second, future work could examine the dynamics of the interpersonal interaction rather than the outcome. Such research would require different methods, such as process observation. In this study, we also focused on the individual level of analysis. Future work could take a dyadic approach and examine how the identities of both employees and customers matter. For example, scholars could examine reciprocal influences such as an employee's experience of identity conflict affecting a customer's identity conflict. Although we proposed and found that the absolute level of identity conflict 
and enhancement individuals experience would affect performance, future work could also take a group-level approach and consider whether the relative level of identity conflict and enhancement compared to one's group members has an effect on performance. Another possibility is to examine how identity conflict and enhancement allow us to work with dissimilar others. Our arguments around roleimmersion and role-taking suggest that it may be easier for people who experience greater identity enhancement to work more effectively with dissimilar others. Current research suggests that when people share an identity, they are more likely to cooperate (Gaertner, Dovidio, Anastasio, Bachman, \& Rust, 1993; Richter, West, Van Dick, \& Dawson, 2006). Identity enhancement and conflict may moderate the effects of similarity between employees and customers on outcomes such as sales (Leonard, Levine, \& Joshi, 2004). It is also possible that identity enhancement may improve our ability to work with dissimilar others because it can substitute for a shared identity. This could have important implications for the role of multiple identities in diverse workplaces.

Third, scholars could also examine relational identification, which is formed through understanding one's own and others' role and personal identities (Sluss \& Ashforth, 2007). This construct provides a complementary yet distinct view of how identities inform interactions. For example, our focus on conflict and enhancement between work-role identities expands upon the focal person's work-role identity, rather than examining relational identity in and of itself. Indeed, identity conflict and enhancement may be related to whether relational identification is positive, negative, or ambivalent. Future work should explore these relationships.

Fourth, future work should examine how our findings extend beyond the identities and the sales context we studied. Our study is situated within the sales context and examined only one type of workrole identity, identification with brands that employees represented to customers. Interestingly, our findings from Study 1 suggest that brand identities are meaningful and may be chronically salient sources of identification for employees over time. Moreover, though specific, people work forms a core part of the economy. The service sector is $66 \%$ of the GDP in high-income countries (Soubbotina, 2004) and in the US, the service economy continues to increase while the goods economy has declined (Henderson, 2013).

\section{Managerial Implications}

Our findings also have important implications for how managers can improve performance in tasks that involve interpersonal interactions. First, managers should pay close attention to the psychological experience of asking employees to take on multiple work roles because managing multiple work-role identities affects how employees interact with customers (e.g., being intrinsically motivated and taking their perspective) and ultimately perform. Second, our findings point to two different levers managers can use to improve performance-decreasing identity conflict and increasing identity enhancement. Identifying with multiple work roles can have beneficial effects, but only when those identities are experienced as highly enhancing and not conflicting. Therefore, managers should first focus on decreasing conflict among identities. They can then help employees actively frame and understand the synergies between their different work-role identities. The fact that we experimentally manipulated identity conflict and enhancement suggests that managers can intervene to affect people's experiences of their multiple identities. Last, the unexpected effects of too much perspective-taking on performance suggests that managers should also pay attention to how perspective-taking helps or hinders employees ability to perform effectively in people work contexts.

\section{CONCLUSION}

As employees navigate the proliferation of roles within the workplace, they increasingly have to grapple with the experience of many competing and complementary identities. Across multiple studies, we demonstrate that identity conflict and enhancement within a person can influence his or her intrinsic motivation, perspective-taking, and ultimately performance in tasks that involve interpersonal interactions. Thus, how employees answer the fundamental question of "who am I," whether in conflicting or enhancing ways, has consequences for how they interact with others and ultimately perform at work.

\section{REFERENCES}

Amabile, T. M. 1988. A model of creativity and innovation in organizations. Research in Organizational Behavior, 10: 123-167.

Amanatullah, E. T., Morris, M. W., \& Curhan, J. R. 2008. Negotiators who give too much: Unmitigated 
communion, relational anxieties, and economic costs in distributive and integrative bargaining. Journal of Personality and Social Psychology, 95: 723-738.

Ashforth, B. E. 2001. Role transitions in organizational life: An identity-based perspective. Mahwah, NJ: Lawrence Erlbaum.

Ashforth, B. E., Harrison, S. H., \& Corley, K. G. 2008. Identification in organizations: An examiniation of four fundamental questions. Journal of Management, 34: $325-374$.

Ashforth, B. E., \& Humphrey, R. H. 1993. Emotional labor in service roles: The influence of identity. Academy of Management Review, 18: 88-115.

Ashforth, B. E., \& Johnson, S. A. (2001). Which hat to wear. In M. A. Hogg \& D. J. Terry (Eds.), Social identity processes in organizational contexts: 32-48. Abingdon, U.K.: Taylor \& Francis.

Ashforth, B. E., Rogers, K. M., Pratt, M. G., \& Pradies, C. 2014. Ambivalence in organizations: A multilevel approach. Organization Science, 25: 1453-1478.

Ashmore, R. D., Deaux, K., \& McLaughlin-Volpe, T. 2004. An organizing framework for collective identity: Articulation and significance of multidimensionality. Psychological Bulletin, 130: 80-114.

Avolio, B. J., Waldman, D. A., \& McDaniel, M. A. 1990. Age and work performance in nonmanagerial jobs: The effects of experience and occupational type. Academy of Management Journal, 33: 407-422.

Axtell, C. M., Parker, S. K., Holman, D., \& Totterdell, P. 2007. Enhancing customer service: Perspective taking in a call centre. European Journal of Work and Organizational Psychology, 16: 141-168.

Baron, R. M., \& Kenny, D. A. 1986. The moderatormediator variable distinction in social psychological research: Conceptual, strategic and statistical considerations. Journal of Personality and Social Psychology, 51: 1173-1182.

Batt, R., Hunter, L. W., \& Wilk, S. 2003. How and when does management matter? Job quality and career opportunities for call center workers. In E. Appelbaum, A. Bernhardt \& R. J. Murnane (Eds.), Low-wage America: How employers are reshaping opportunity in the workplace: 270-315. New York, NY: Russell Sage.

Baumeister, R. F. 2002. Ego depletion and self-control failure: An energy model of the self's executive function. Self and Identity, 1: 129-136.

Baumeister, R. F., Bratslavsky, E., Muraven, M., \& Tice, D. M. 1998. Ego depletion: Is the active self a limited resource? Journal of Personality and Social Psychology, 74: 1252-1265.

Bauer, T. N., \& Green, S. G. 1996. Development of leadermember exchange: A longitudinal test. Academy of Management Journal, 39: 1538-1567.
Benet-Martinez, V., \& Haritatos, J. 2005. Bicultural Identity Integration (BII): Components and psychosocial antecedents. Journal of Personality, 73: 1015-1050.

Benet-Martinez, V., Lee, F., \& Leu, J. 2006. Biculturalism and cognitive complexity expertise in cultural representation. Journal of Cross-Cultural Psychology, 37: 386-407.

Berinsky, A. J., Huber, G. A., \& Lenz, G. S. 2012. Evaluating online labor markets for experimental research: Amazon.com's Mechanical Turk. Political Analysis, 20: 351-368.

Blader, S. L. (2007). Let's not forget the "me" in "team": Investigating the interface of individual and collective identity. In C. Bartel, S. Blader \& A. Wrzesniewski (Eds.), Identity and the modern organization: pp. 61-84). Mahwah, NJ: Lawrence Erlbaum Associates.

Brewer, M. B., \& Gardner, W. 1996. Who is this "we"? Levels of collective identity and self representations. Journal of Personality and Social Psychology, 71: 83-93.

Brickson, S. L. 2013. Athletes, best friends, and social activists: An integrative model accounting for the role of identity in organizational identification. Organization Science, 24: 226-245.

Brook, A. T., Garcia, J., \& Fleming, M. A. 2008. The effects of multiple identities on psychological well-being. Personality and Social Psychology Bulletin, 34: 1588-1600.

Brotheridge, C. M., \& Grandey, A. A. 2002. Emotional labor and burnout: Comparing two perspectives of "people work". Journal of Vocational Behavior, 60: 17-39.

Buhrmester, M., Kwang, T., \& Gosling, S. D. 2011. Amazon's Mechanical Turk: A new source of inexpensive, yet high-quality, data? Perspectives on Psychological Science, 6: 3-5.

Burke, P. J., \& Reitzes, D. C. 1991. An identity theory approach to commitment. Social Psychology Quarterly, 54: 239-251.

Burke, P. J., \& Stets, J. 2009. Identity theory. New York, NY: Oxford University Press.

Callero, P. L. 1985. Role-identity salience. Social Psychology Quarterly, 48: 203-215.

Carver, C. S., \& White, T. L. 1994. Behavioral inhibition, behavioral activiation, and affective responses to impending reward and punishment: The BIS/BAS Scales. Journal of Personality and Social Psychology, 67: 319-333.

Casler, K., Bickel, L., \& Hackett, E. 2013. Separate but equal? A comparison of participants and data gathered via Amazon's MTurk, social media, and face-to-face 
behavioral testing. Computers in Human Behavior, 29: 2156-2160.

Cast, A. D. 2004. Role-taking and interaction. Social Psychology Quarterly, 67: 296-309.

Cast, A. D., \& Burke, P. J. 2002. A theory of self-esteem. Social Forces, 80: 1041-1068.

Cheng, C., Sanchez-Burks, J., \& Lee, F. 2008. Connecting the dots within: Creative performance and identity integration. Psychological Science, 19: 1178-1184.

Creary, S., Caza, B., \& Roberts, L. 2015. Out of the box? How managing a subordinate's multiple identities affects the quality of a manager-subordinate relationship. Academy of Management Review, 40: 538-562.

Curhan, J. R., Neale, M. A., Ross, L., \& Rosencranz-Engelmann, J. 2008. Relational accommodation in negotiation: Effects of egalitarianism and gender on economic efficiency and relational capital. Organizational Behavior and Human Decision Processes, 107: 192-205.

Czikszentmihalyi, M. 1982. Intrinsic motivation and effective teaching: A flow analysis. New Directions for Teaching and Learning, 10: 15-26.

Davis, M. H. 1983. Measuring individual differences in empathy: Evidence for a multidimensional approach. Journal of Personality and Social Psychology, 44: 113-126.

Deci, E. L., \& Ryan, R. M. 1995. Human autonomy: The basis for true self-esteem. In M. H. Kernis (Ed.), Efficacy, agency, and self-esteem: 31-49. New York, NY: Plenum Press.

Deci, E. L., \& Ryan, R. M. 2000. The "what" and "why" of goal pursuits: Human needs and the selfdetermination of behavior. Psychological Inquiry, 11: $227-268$.

Dutton, J. E., Roberts, L. M., \& Bednar, J. S. 2010. Pathways for positive identity construction at work: Four types of positive identity and the building of social resources. Academy of Management Review, 35: 265-293.

Falk, D. R., \& Johnson, D. W. 1977. The effects of perspective-taking and egocentrism on problem solving in heterogeneous and homogeneous groups. The Journal of Social Psychology, 102: 63-72.

Festinger, L. 1957. A theory of cognitive dissonance. Oxford, U.K.: Row, Peterson \& Co.

Fiol, C. M., Pratt, M. G., \& O’Connor, E. J. 2009. Managing intractable identity conflicts. Academy of Management Review, 34: 32-55.

Fong, C. T. 2006. The effects of emotional ambivalence on creativity. Academy of Management Journal, 49: 1016-1030.
Gaertner, S. L., Dovidio, J. F., Anastasio, P. A., Bachman, B. A., \& Rust, M. C. 1993. The common ingroup identity model: Recategorizaiton and the reduction of intergroup bias. European Review of Social Psychology, 4: 1-26.

Gagné, M., \& Deci, E. L. 2005. Self-determination theory and work motivation. Journal of Organizational Behavior, 26: 331-362.

Gaither, S. E., Remedios, J. D., Sanchez, D. T., \& Sommers, S. R. 2015. Thinking outside the box: Multiple identity mind-sets affect creative problem solving. Social Psychological \& Personality Science, 6: 596-603.

Galinsky, A. D., Maddux, W. W., Gilin, D., \& White, J. B. 2008. Why it pays to get inside the head of your opponent the differential effects of perspective taking and empathy in negotiations. Psychological Science, 19: 378-384.

Galinsky, A. D., \& Moskowitz, G. B. 2000. Perspectivetaking: Decreasing stereotype expression, stereotype accessibility, and in-group favoritism. Journal of Personality and Social Psychology, 78: 708-24.

Gelfand, M. J., Major, V. S., Raver, J. L., Nishii, L. H., \& O'Brien, K. 2006. Negotiating relationally: The dynamics of the relational self in negotiations. Academy of Management Review, 31: 427-451.

George, E., \& Chattopadhyay, P. 2005. One foot in each camp: The dual identification of contract workers. Administrative Science Quarterly, 50: 68-99.

George, J. M., \& Zhou, J. 2002. Understanding when bad moods foster creativity and good ones don't: The role of context and clarity of feelings. The Journal of Applied Psychology, 87: 687-97.

Goffman, E. 1961. Encounters: Two studies in the sociology of interaction. New York, NY: BobbsMerrill Co.

Goodman, J. K., Cryder, C. E., \& Cheema, A. 2013. Data collection in a flat world: The strengths and weaknesses of Mechanical Turk samples. Journal of Behavioral Decision Making, 26: 213-224.

Grant, A. M. 2008. Does intrinsic motivation fuel the prosocial fire? Motivational synergy in predicting persistence, performance, and productivity. The Journal of Applied Psychology, 93: 48-58.

Grant, A. M., \& Berry, J. W. 2011. The necessity of others is the mother of invention: Intrinsic and prosocial motivations, perspective taking, and creativity. Academy of Management Journal, 54: 73-96.

Grant, A. M., \& Rothbard, N. P. 2013. When in doubt, seize the day? Security values, prosocial values, and proactivity under ambiguity. The Journal of Applied Psychology, 98: 810-819. 
Gray, J. R., Burgess, G. C., Schaefer, A., Yarkoni, T., Larsen, R. J., \& Braver, T. S. 2005. Affective personality differences in neural processing efficiency confirmed using fMRI. Cognitive, Affective \& Behavioral Neuroscience, 5: 182-190.

Greenhaus, J. H., \& Beutell, N. J. 1985. Sources of conflict between work and family roles. Academy of Management Review, 10: 76-88.

Greenhaus, J. H., \& Powell, G. 2006. When work and family are allies: A theory of work-family enrichment. Academy of Management Review, 31: 7292.

Guay, F., Vallerand, R. J., \& Blanchard, C. 2000. On the assessment of situational intrinsic and extrinsic motivation: The Situational Motivation Scale (SIMS). Motivation and Emotion, 24: 175-213.

Heimer, K., \& Matsueda, R. L. 1994. Role-taking, role commitment, and delinquency: A theory of differential social control. American Sociological Review, 59: 365-390.

Hekman, D. R., Aquino, K., Owens, B. P., Mitchell, T. R., Schilpzand, P., \& Leavitt, K. 2010. An examination of whether and how racial and gender biases influence customer satisfaction. Academy of Management Journal, 53: 238-264.

Henderson, R. 2013. Industry employment and output projections to 2022. Monthly Labor Review, December. Available at: http://www.bls.gov/opub/mlr/ 2013/article/pdf/industry-employment-and-outputprojections-to-2022.pdf.

Hirsh, J. B., \& Kang, S. K. 2016. Mechanisms of identity conflict uncertainty, anxiety, and the behavioral inhibition system. Personality and Social Psychology Review, 20: 223-244.

Hochschild, A. R. 1983. The managed heart: Commercialization of human feeling, with a new afterword. Berkeley, CA: University of California Press.

Horton, K. E., Bayerl, P. S., \& Jacobs, G. 2014. Identity conflicts at work: An integrative framework. Journal of Organizational Behavior, 35(S1): S6-S22.

Hugenberg, K., \& Bodenhausen, G. V. 2004. Category membership moderates the inhibition of social identities. Journal of Experimental Social Psychology, 40: 233-238.

Hughes, D. E., \& Ahearne, M. 2010. Energizing the reseller's sales force: The power of brand identification. Journal of Marketing, 74: 81-96.

James, W. 1983. The consciousness of self. In W. James (Ed.), The principles of psychology: 291-401. Cambridge, MA: Harvard University Press.

Jasmand, C., Blazevic, V., \& de Ruyter, K. 2012. Generating sales while providing service: A study of customer service representatives' ambidextrous behavior. Journal of Marketing, 76: 20-37.

Johnson, M. D., Morgeson, F. P., Ilgen, D. R., Meyer, C. J., \& Lloyd, J. W. 2006. Multiple professional identities: Examining differences in identification across workrelated targets. The Journal of Applied Psychology, 91: 498-506.

Johnson, S. A., \& Ashforth, B. E. 2008. Externalization of employment in a service environment: The role of organizational and customer identification. Journal of Organizational Behavior, 29: 287-309.

Joshi, A., Liao, H., \& Jackson, S. E. 2006. Cross-level effects of workplace diversity on sales performance and pay. Academy of Management Journal, 49: $459-481$.

Kahn, W. A. 1990. Psychological conditions of personal engagement and disengagement at work. Academy of Management Journal, 33: 692-724.

Katz, D., \& Kahn, R. L. 1978. The social psychology of organizations. New York, NY: Wiley.

Kreft, I. G., Kreft, I., \& de Leeuw, J. 1998. Introducing multilevel modeling. Thousand Oaks, CA: Sage Publications.

Kreiner, G. E., Hollensbe, E. C., \& Sheep, M. L. 2006. Where is the "me" among "we"? Identity work and the search for optimal balance. Academy of Management Journal, 49: 1031-1057.

LeBreton, J. M., \& Senter, J. L. 2008. Answers to 20 questions about interrater reliability and interrater agreement. Organizational Research Methods, 11: 815-852.

Leonard, J. S., Levine, D. I., \& Joshi, A. 2004. Do birds of a feather shop together? The effects on performance of employees' similarity with one another and with customers. Journal of Organizational Behavior, 25: 731-754.

Leonard, N. H., Beauvais, L. L., \& Scholl, R. W. 1999. Work motivation: The incorporation of self-concept-based processes. Human Relations, 52: 969-998.

Lipponen, J., Helkama, K., Olkkonen, M. E., \& Juslin, M. 2005. Predicting the different profiles of organizational identification: A case of shipyard subcontractors. Journal of Occupational and Organizational Psychology, 78: 97-112.

Lount, R. B., Sheldon, O. J., Rink, F., \& Phillips, K. W. 2015. Biased perceptions of racially diverse teams and their consequences for resource support. Organization Science, 26, 1351-1364.

Loyd, D. L., Wang, C. S., Phillips, K. W, \& Lount, R. B. (2013). Social category diversity promotes pre- meeting elaboration: The role of relationship focus. Organization Science, 24: 757-772. 
Lyubomirsky, S., \& Nolen-Hoeksema, S. 1993. Selfperpetuating properties of dysphoric rumination. Journal of Personality and Social Psychology, 65: 339.

Mael, F., \& Ashforth, B. E. 1992. Alumni and their alma mater: A partial test of the reformulated model of organizational identification. Journal of Organizational Behavior, 13: 103-123.

Marcussen, K. 2006. Identities, self-esteem, and psychological distress: An application of identity-discrepancy theory. Sociological Perspectives, 49: 1-24.

Marks, S. R. 1977. Multiple roles and role strain: Some notes on human energy, time and commitment. American Sociological Review, 42: 921-936.

Markus, H., \& Nurius, P. 1986. Possible selves. The American Psychologist, 41: 954-969.

Marsh, D. T., Serafica, F. C., \& Barenboim, C. 1980. Effect of perspective-taking training on interpersonal problem solving. Child Development, 51: 140-145.

McEvoy, G. M., \& Cascio, W. F. 1989. Cumulative evidence of the relationship between employee age and job performance. The Journal of Applied Psychology, 74: 11 .

McGrath, J. E. 1981. Dilemmatics: The study of research choices and dilemmas. The American Behavioral Scientist, 25: 179-210.

McKay, P. F., Avery, D. R., \& Morris, M. A. 2008. Mean racial-ethnic differences in employee sales performance: The moderating role of diversity climate. Personnel Psychology, 61: 349-374.

Mead, G. H. 1934. Mind, self and society. Chicago, IL: University of Chicago Press.

Muthén, L. K., \& Muthén, B. O. (2012). Mplus. The comprehensive modelling program for applied researchers: User's guide, 5. Los Angeles, CA: Muthén \& Muthén.

Ng, T. W., \& Feldman, D. C. 2008. The relationship of age to ten dimensions of job performance. The Journal of Applied Psychology, 93: 392-423.

Ng, T. W., \& Feldman, D. C. 2010. Organizational tenure and job performance. Journal of Management, 36: 1220-1250.

Parker, S. K., \& Axtell, C. M. 2001. Seeing another viewpoint: Antecedents and outcomes of employee perspective taking. Academy of Management Journal, 44: 1085-1100.

Petriglieri, J. 2011. Under threat: Responses to and the consequences of threats to individuals' identities. Academy of Management Review, 34: 641-662.

Pratt, M. G., \& Foreman, P. O. 2000. Classifying managerial responses to multiple organizational identities. Academy of Management Review, 25: 18-42.
Preacher, K. J., Zhang, Z., \& Zyphur, M. J. 2011. Alternative methods for assessing mediation in multilevel data: The advantages of multilevel SEM. Structural Equation Modeling, 18: 161-182.

Preacher, K. J., Zyphur, M. J., \& Zhang, Z. 2010. A general multilevel SEM framework for assessing multilevel mediation. Psychological Methods, 15: 209-233.

Rafaeli, A. 1989. When cashiers meet customers: An analysis of the role of supermarket cashiers. Academy of Management Journal, 32: 245-273.

Ramarajan, L. 2014. Past, present and future research on multiple identities: Toward an intrapersonal network approach. The Academy of Management Annals, 8: $1-71$.

Ramarajan, L., Berger, I., \& Greenspan, I. 2017. Multiple identity configurations: The benefits of focused enhancement for prosocial behavior. Organization Science, 28: 495-513.

Reitzes, D. C., \& Burke, P. J. 1980. College student identity measurement and implications. Sociological Perspectives, 23: 45-66.

Richter, A. W., West, M. A., Van Dick, R., \& Dawson, J. F. 2006. Boundary spanners' identification, intergroup contact, and effective intergroup relations. Academy of Management Journal, 49: 12521269.

Rosenberg, S. 1997. Multiplicity of selves. In R. D. Ashmore \& L. Jussim (Eds.), Self and identity: Fundamental issues. Rutgers series on self and social identity: 23-45. New York, NY: Oxford University Press.

Rotemberg, J. J. 2010. Persuasion and empathy in salesperson-customer interactions. Cambridge, MA: National Bureau of Economic Research.

Rothbard, N. P. 2001. Enriching or depleting? The dynamics of engagment in work and family roles. Administrative Science Quarterly, 46: 655-684.

Rothbard, N. P., \& Edwards, J. R. 2003. Investment in work and family roles: A test of identity and utilitarian motives. Personnel Psychology, 56: 699-729.

Rothbard, N. P., \& Ramarajan, L. 2009. Checking your identities at the door? Positive relationships between nonwork and work identities. In L. M. Roberts \& J. E. Dutton (Eds.), Exploring positive identities and organizations: 125-144. New York, NY: Psychology Press.

Rothman, N. B., \& Melwani, S. 2016. Feeling mixed, ambivalent and in flux: The social functions of emotional complexity for leaders. Academy of Management Review, 42: 175-189.

Ruderman, M. N., Ohlott, P. J., Panzer, K., \& King, S. N. 2002. Benefits of multiple roles for managerial 
women. Academy of Management Journal, 45: 369-386.

Russell, C. J., \& Kuhnert, K. W. 1993. Integrating skill acquisition and perspective taking capacity in the development of leaders. The Leadership Quarterly, 3: 335-353.

Scott, S. 2015. Negotiating identity: Symbolic interactionist approaches to social identity. Cambridge, U.K.: Polity Press.

Settles, I. H. 2004. When multiple identities interfere: The role of identity centrality. Personality and Social Psychology Bulletin, 30: 487-500.

Shih, M., \& Sanchez, D. T. 2005. Perspectives and research on the positive and negative implications of having multiple racial identities. Psychological Bulletin, 131: 569-597.

Sluss, D. M., \& Ashforth, B. E. 2007. Relational identity and identification: Defining ourselves through work relationships. Academy of Management Review, 32: 9-32.

Sluss, D. M., Ployhart, R. E., Cobb, M. G., \& Ashforth, B. E. 2012. Generalizing newcomers' relational and organizational identifications: Processes and prototypicality. Academy of Management Journal, 55: 949-975.

Sluss, D. M., van Dick, R., \& Thompson, B. S. 2010. Role theory in organizations: A relational perspective. In S. Zedeck (Ed.), APA handbook of industrial and organizational psychology: 505534. Washington, DC: American Psychological Association.

Soubbotina, T. P. 2004. Beyond economic growth: an introduction to sustainable development. WBI learning resources series. Washington, DC: World Bank.

Spencer, S. J., Zanna, M. P., \& Fong, G. T. 2005. Establishing a causal chain: Why experiments are often more effective than mediational analyses in examining psychological processes. Journal of Personality and Social Psychology, 89: 845-851.

Spiro, R. L., \& Weitz, B. A. 1990. Adaptive selling: Conceptualization, measurement, and nomological validity. Journal of Marketing Research, 27: 61-69.

Staw, B. M., Sandelands, L. E., \& Dutton, J. E. 1981. Threat rigidity effects in organizational behavior: A multilevel analysis. Administrative Science Quarterly, 26: 501-524.

Stryker, S. 2008. From mead to a structural symbolic interactionism and beyond. Annual Review of Sociology, 34: 15-31.

Stryker, S., \& Burke, P. J. 2000. The past, present and future of an identity theory. Social Psychology Quarterly, 63: 284-297.
Stryker, S., \& Serpe, R. T. 1982. Commitment, identity salience and role behavior: Theory and research example. In W. Ickes \& E. S. Knowles (Eds.), Personality, roles, and social behavior: 199-218. New York, NY: Springer-Verlag.

Stryker, S., \& Serpe, R. T. 1994. Identity salience and psychological centrality: Equivalent, overlapping, or complementary concepts? Social Psychology Quarterly, 57: 16-35.

Stryker, S., \& Statham, A. 1985. Symbolic interaction and role theory. In G. Lindzey \& E. Aronson (Eds.), Handbook of social psychology: 311-378. New York, NY: Penguin Random House.

Sturman, M. C. 2003. Searching for the inverted U-shaped relationship between time and performance: Metaanalyses of the experience/performance, tenure/ performance, and age/performance relationships. Journal of Management, 29: 609-640.

Tadmor, C. T., Tetlock, P. E., \& Peng, K. 2009. Acculturation strategies and integrative complexity: The cognitive implications of biculturalism. Journal of Cross-Cultural Psychology, 40: 105-139.

Tajfel, H., \& Turner, J. C. 1987. The social identity theory of intergroup behavior. In S. Worchel \& W. G. Austin (Eds.), Psychology of intergroup relations: 7-24. Chicago, IL: Nelson-Hall.

Taylor, S. E. 1991. Asymmetrical effects of positive and negative events: The mobilization-minimization hypothesis. Psychological Bulletin, 110: 67-85.

Thoits, P. A. 1983. Multiple identities and psychological well-being: A reformulation and test of the social isolation hypothesis. American Sociological Review, 48: 174-187.

Thoits, P. A. 1991. On merging identity theory and stress research. Social Psychology Quarterly, 54: 101-112.

Tiedje, L. B., Wortman, C. B., Downey, G., Emmons, C., Biernat, M., \& Lang, E. 1990. Women with multiple roles: Role-enhancement perceptions, satisfaciton, and mental-health. Journal of Marriage and the Family, 52: 63-72.

Turner, R. H. 1956. Role-taking, role standpoint, and reference-group behavior. American Journal of Sociology, 61: 316-328.

Vaughan, D. 1996. The challenger launch decision: Risky technology, culture, and deviance and NASA. Chicago, IL: University of Chicago Press.

Waterman, A. S. 1990. Personal expressiveness: Philosophical and psychological foundations. Journal of Mind and Behavior, 11: 47-74.

Watson, D., Clark, L. A., \& Tellegen, A. 1988. Development and validation of brief measures of positive and negative affect: The PANAS Scales. Journal 
of Personality and Social Psychology, 54: 10631070.

Wharton, A. S. 2009. The sociology of emotional labor. Annual Review of Sociology, 35: 147-165.

Wilk, S. L., \& Moynihan, L. M. 2005. Display rule "regulators": The relationship between supervisors and worker emotional exhaustion. The Journal of Applied Psychology, 90: 917-27.

Williams, M. 2012. Perspective taking: Building positive interpersonal connections and trustworthiness one interaction at a time. In K. Cameron \& G. Spreitzer (Eds.), Oxford handbook of positive organizational scholarship. New York, NY: Oxford University Press.

Williams, M., \& Polman, E. 2015. Is it me or her? How gender composition evokes interpersonally sensitive behavior on collaborative cross-boundary projects. Organization Science, 26: 334-355.

Yagil, D., \& Medler-Liraz, H. 2013. Moments of truth: Examining transient authenticity and identity in service encounters. Academy of Management Journal, 56: 473-497.

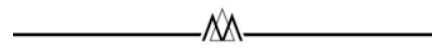

Lakshmi Ramarajan (lramarajan@hbs.edu) is an assistant professor of organizational behavior at Harvard Business School, Harvard University. She received her $\mathrm{PhD}$ from the Wharton School, University of Pennsylvania. Her research examines the management and consequences of individuals' multiple identities in organizations.

Nancy P. Rothbard (nrothbard@wharton.upenn.edu) is the David Pottruck Professor and Chair of the Management Department at the Wharton School, University of Pennsylvania. She received her $\mathrm{PhD}$ from the University of Michigan. Her work focuses on people's engagement in multiple roles and how they navigate the boundaries between them.

Steffanie L. Wilk (wilk.17@osu.edu) is an associate professor of management and human resources at The Ohio State University. She received her $\mathrm{PhD}$ from the University of Minnesota. Her research interests include emotional labor, employee burnout and turnover, social relationships at work, and the particular challenges of telephone-mediated service work.

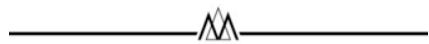

Appendix A: Identity Conflict and Enhancement Items

\begin{tabular}{lcc}
\hline \multicolumn{1}{c}{ Identity conflict } & Conflict factor loadings (F1) & Enhancement factor loadings (F2) \\
\hline I struggle to maintain a(n) A and B way of doing things. & $\underline{0.84}$ & 0.26 \\
Life would be easier if I was a(n) A OR a(n) B. & $\underline{0.86}$ & 0.05 \\
Being a "good" A interferes with being "good" B. & $\underline{0.83}$ & 0.06 \\
I feel an A way of doing things and a B way of doing & Conflict factor loadings (F1) & Enhancement factor loadings (F2) \\
$\quad$ things are opposed. & -0.21 & $\underline{0.71}$ \\
Identity enhancement & 0.10 & $\underline{0.87}$ \\
I am glad I am both a(n) A and a(n) B. & 0.22 & $\underline{0.80}$ \\
I rely on both a(n) A and a(n) B way of doing things & 0.24 \\
I am a better A because of my B identity. & $\underline{0.85}$ \\
I appreciate being a(n) A more because I am also a(n) B. & \\
\hline
\end{tabular}

Notes: A pre-test sample $(n=147)$ was asked to list their identities and then pick the five most important identities to them and then respond to the above items regarding identity conflict and enhancement for each pair of identities. Factor loadings were based on exploratory factor analyses of one pair of identities, similar patterns were obtained for all ten pairs. Confirmatory factor analyses (CFA) on a separate sample $(n=$ 210) indicated that the two-factor structure was supported. A CFA was conducted on the conflict and compatibility items for each pair of identities to validate the two-factor solution resulting from the EFA. The following fit statistics were examined: comparative fit index (CFI), RMSEA and standardized root mean-square residual (SRMR). The CFA showed that the one factor model had poor fit $\left(\chi^{2}(17)=403.98, p<.001\right.$; $\mathrm{CFI}=.68 ; \mathrm{RMSEA}=.36, p<.001 ; \mathrm{SRMR}=.18)$. The two-factor model fit the data well $\left(\chi^{2}(16)=24.65, p=.07 ; \mathrm{CFI}=.99 ; \mathrm{RMSEA}=.06, p=.37\right.$; $\mathrm{SRMR}=.03)$. The $\chi^{2}$ difference tests indicated that the two-factor model fit the data significantly better than a one-factor model, the difference in $\chi^{2}(1)=379, p<.001$. 


\section{APPENDIX B \\ IDENTITY MANIPULATIONS}

To reinforce the manipulation language reported in the text for Studies 2a and 2b, each condition was accompanied by the following visual representations of identity conflict and enhancement. See Figures B1 and B2.

\section{FIGURE B1 \\ Identity Conflict Condition}

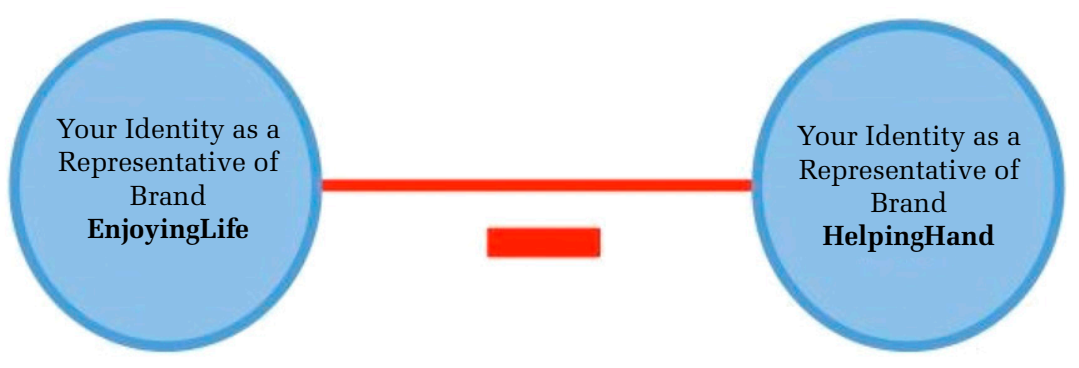

FIGURE B2

Identity Enhancement Condition

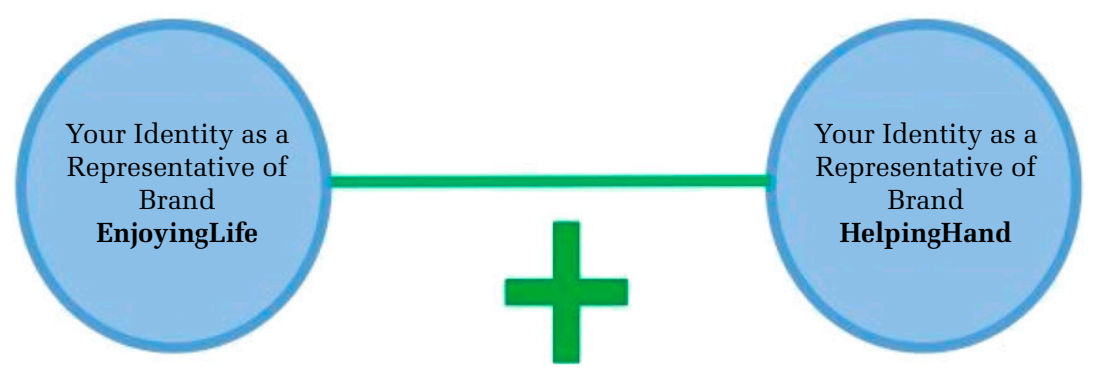

\section{APPENDIX C}

\section{THE JOINT EFFECTS OF IDENTITY CONFLICT AND ENHANCEMENT ON SALES}

\section{Sample}

Participants were 596 adults recruited through Amazon MTurk. Their average age was 34 years $(S D=10.57)$, $44.6 \%$ were female, and all were located in the United States. Participants were paid $\$ 1.00$ for their participation.

\section{Procedure}

We used a $3 \times 1$ between-subjects design: identity conflict, identity enhancement, and, here, the third condition was a joint identity conflict and enhancement condition.
We used the same procedure and manipulations as described above in Appendix B, Studies 1 and 2, except for the joint conflict and enhancement condition, which read: "You find identifying with both brands to be both highly enhancing AND highly conflicting. For example, you find that being a customer service representative for Brand A both interferes with AND complements Brand B. You find that at times Brand A is strongly compatible with AND at other times strongly opposed to Brand B. You both struggle AND appreciate the opportunity to represent both Brands A and B simultaneously. In sum, working on both brands is at times highly enhancing AND at other times highly conflicting."

\section{Measures}

Identity conflict and enhancement. We measured conflict and enhancement using the same items from Appendix A, Study 1. Cronbach's $\alpha$ was .91 for identity 
conflict and .77 for identity enhancement. $\mathrm{M}_{\mathrm{Conf}}=4.03$ $(S D=.69)$ and $\mathrm{M}_{\text {Enh }}=1.98(S D=.79)$.

Intention to sell. We measured intention to sell with the item: How likely are you to try to sell the customer Brand B ( 1 = highly unlikely, $7=$ highly likely). $\mathrm{M}=4.95$ $(S E=1.43)$. We standardized this variable for ease of interpretation of the results.

\section{Results}

Manipulation check. The manipulation check showed that participants responded as expected to the identity conflict and enhancement conditions. The overall ANOVAs showed that the means for identity conflict
$\left(\mathrm{F}_{2,593}=457.29, p<.001\right)$ and identity enhancement $\left(\mathrm{F}_{2,593}=165.04, p<.001\right)$ were significantly different across all three conditions.

Identity conflict and enhancement predict intention to sell. We found that the experimental condition significantly predicted intention to sell $\left(\mathrm{F}_{2,593}=4.25, p<\right.$ .05). Specifically, those in the identity conflict condition reported lower intention to sell compared to those in the identity enhancement condition ( $t=2.45, p<.05$ ), but were not significantly different from the identity conflict and Enhancement condition ( $t=.21, p=.84$ ). However, those in the identity enhancement condition reported significantly greater intention to sell than those in the identity conflict and enhancement conditions $(t=2.57, p<.05)$. See figure C1.

FIGURE C1

Identity Conflict and Enhancement predict Intention to Sell

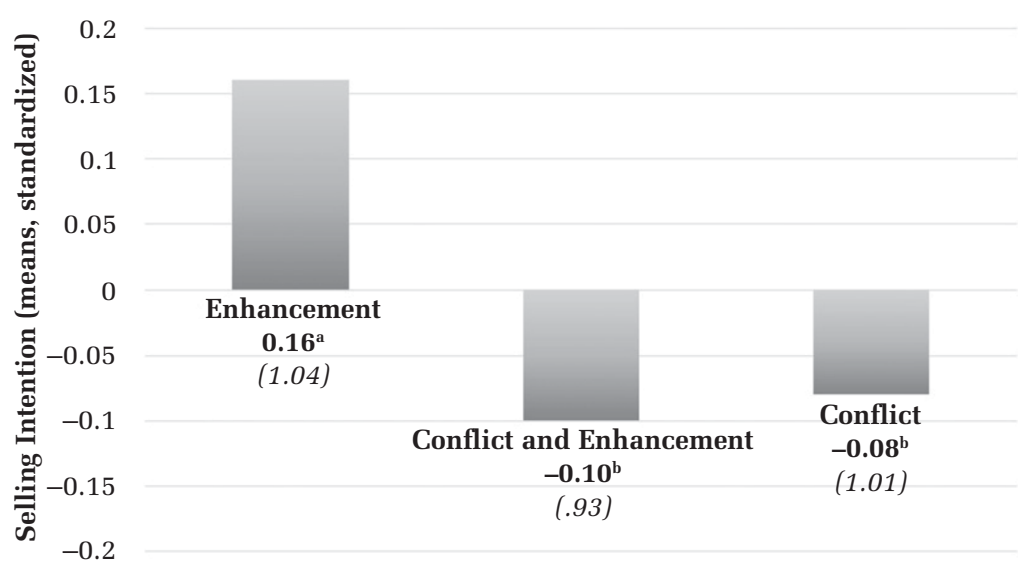

